Portland State University

PDXScholar

$5-11-1978$

\title{
The Effect of Background Noise on Children's Selective Listening Behavior
}

Cathryn A. Chartier

Portland State University

Follow this and additional works at: https://pdxscholar.library.pdx.edu/open_access_etds

Part of the Psychology Commons, and the Speech Pathology and Audiology Commons Let us know how access to this document benefits you.

\section{Recommended Citation}

Chartier, Cathryn A., "The Effect of Background Noise on Children's Selective Listening Behavior" (1978). Dissertations and Theses. Paper 2852.

https://doi.org/10.15760/etd.2845

This Thesis is brought to you for free and open access. It has been accepted for inclusion in Dissertations and Theses by an authorized administrator of PDXScholar. Please contact us if we can make this document more accessible: pdxscholar@pdx.edu. 
AN ABSTRACT OF THE THESIS of Cathryn A. Chartier for the Master of Science in Speech Communication, Emphasis in Speech Pathology/Audiology, presented May 11, 1978.

Title: The Effect of Background Noise on Children's Selective Listening Behavior.

APPROVED BY MEMBERS OF THE THESIS COMMITTEE:
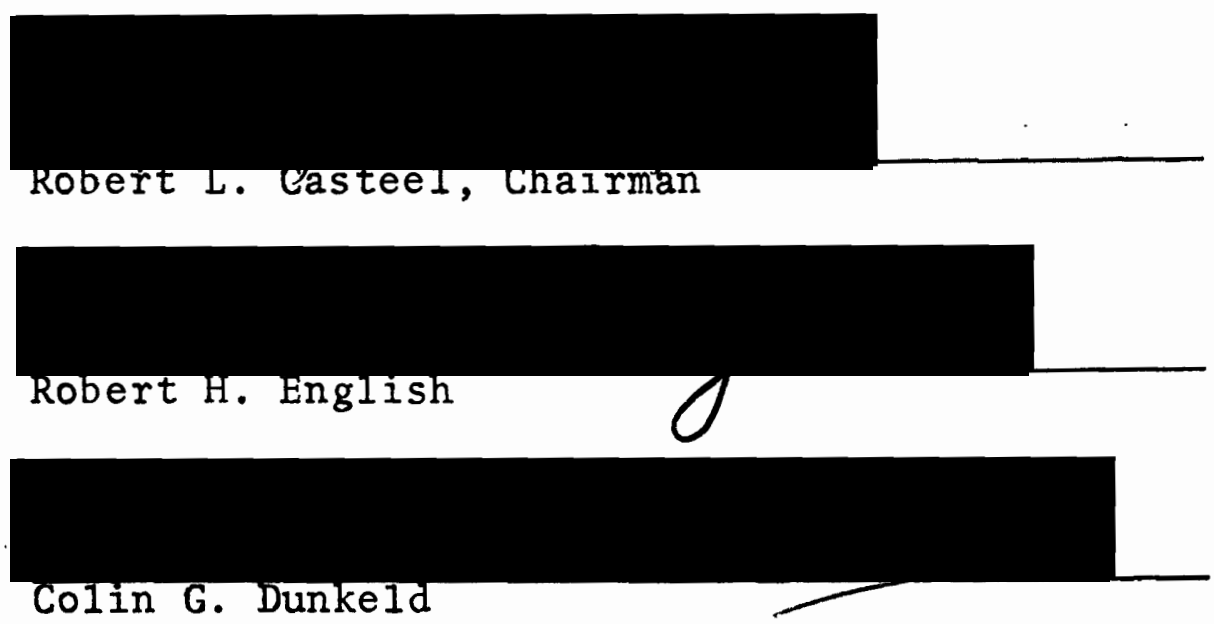

This study investigated the effect of distracting linguistic background noise on children's ability to perform three-part commands. A total of twelve first grade subjects, six "normal" and six reading delayed, were individually administered a series of twenty, three-part commands. Each child performed once in quiet and once in a noise environment, and the performances in those two conditions were compared. 
The results of the study showed a significant difference $(p<.0005)$ between following the directions in quiet and in noise, with all children's level of accuracy decreasing under conditions of noise. The difference $(p .>.05)$ between "normal" subjects' and reading delayed subjects' performance levels was not significant in either quiet or in noise conditions. The presence of noise, then, appeared to interfere with both groups' performance equally. 
THE EFFECT OF BACKGROUND NOISE ON CHILDREN'S SELECTIVE LISTENING BEHAVIOR

\section{by}

CATHRYN A. CHARTIER

A thesis submitted in partial fulfillment of the requirements for the degree of

\section{MASTER OF SCIENCE IN SPEECH COMMUNICATION: \\ with an emphasis in \\ SPEECH PATHOLOGY/AUDIOLOGY}

Portland State University 
TO THE OFFICE OF GRADUATE STUDIES AND RESEARCH:

The members of the Committee approve the thesis of Cathryn A. Chartier presented May 11, 1978.
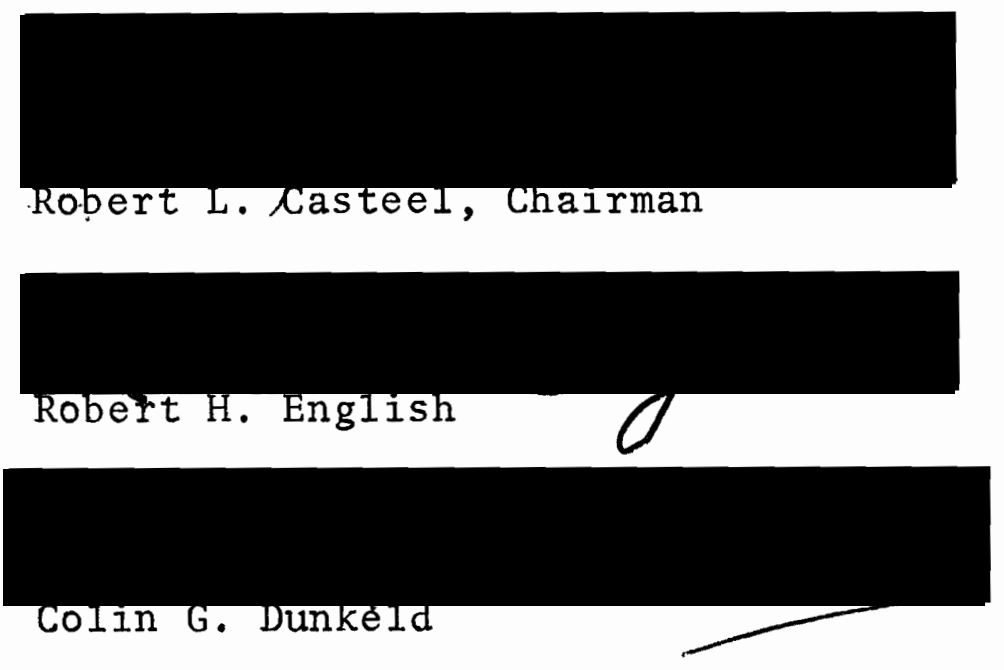

APPROVED :

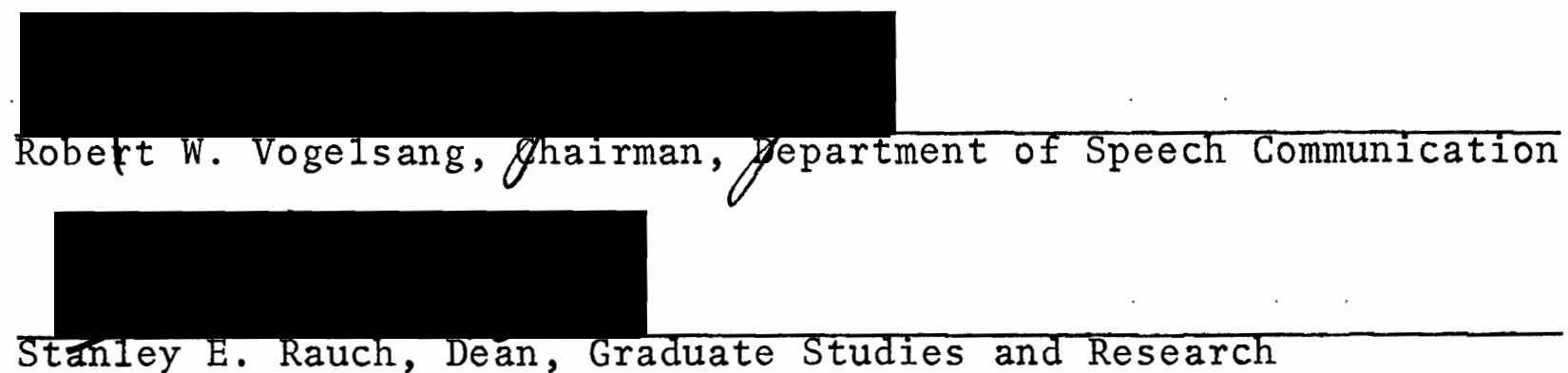




\section{ACKNOWLEDGMENTS}

Without so much help from so many individuals, this study could not have been undertaken. First, to Dr. Robert Casteel, my advisor and committee chairman, I extend sincere appreciation for his continued interest and encouragement, and for his assistance with the many details of this project. And to Dr. Robert English, a member of the committee, a thank you for first luring me into this profession by means of Shakespeare-1aced lectures, and for sending me out into the world with a grammatically correct and "tightened up" thesis. I also thank Dr. Al Hicks, who so generously shared his technical expertise to assist me in the design and instrumentation of this study. Dr. Jack Hegrenes, that indefatigable statistician, deserves special appreciation for his forfeited lunch hours and his invaluable help in the statistical analysis of this investigation. Thanks go, also, to Deon Shope, a fellow graduate student, whose recorded reading was an integral part of this study.

Also, to the principals, Mr. William Jackson and $\mathrm{Mr}$. Claude Buckley, and to the secretaries, teachers, parents, and students of East and West Gresham Grade Schools, I express deep appreciation for their patience and cooperation. I must thank Barbara Lolich and Ruth Ayers, ELP specialists, and their aides for their generous donation of time and 
effort on my behalf. Thank you, also, to $\mathrm{Mr}$. Cronin, the librarian at East Gresham Grade School for the use of the library rooms. And to $\mathrm{Mr}$. Bill Otos, speech pathologist at both schools, I extend special thanks for his assistance in obtaining the facilities and resources upon which this study depended.

Finally, my loved ones deserve my deepest gratitude. I had wanted to present this finished project to my father, as a small gift of love, in appreciation for his quiet pride in me. Had he lived to receive it, he would have secured from me these thanks too seldom said. And to my mother I express great love and appreciation for her abiding faith in me, and for her support of all my aspirations, this present work among them. My brother, Glenn, deserves a note of thanks, as well, for his attitude of indifference, which has kept me from taking myself and my.contribution to the "world of research" too seriously. On my husband, Joseph, I confer sainthood. It is he who has met bad temper with patience, tears with comfort, and discouragement with hope throughout my graduate program. Were it possible, this thesis and my Master's degree would bear his name along with mine.

To all of these individuals $I$ express sincere thanks. Their giving has enriched my life, and their combined efforts have made this research possible. 
TABLE OF CONTENTS

PAGE

ACKNOWLEDGMENTS

LIST OF TABLES

CHAPTER

I INTRODUCTION. . . . . . . . . . . . . . . 1

STATEMENT OF PURPOSE. . . . . . . . . . 4

DEFINITION OF TERMS • • . . . . . . . . . 4

I I REVIEW OF THE LITERATURE. • . • . . • . • 6

HISTORY OF RESEARCH IN AUDITORY PRO-

CESSING . . . . . . . . . . . . . 6

THEORIES OF AUDITORY PERCEPTION AND

ATTENTION •. • . . . . . . . . . . . 9

ATTENTION AND LEARNING. . . . . . . . 13

LISTENING, LANGUAGE, AND READING. • . • 16

I I METHODS AND PROCEDURES. . . . . . . . . . 28

METHODS . . . . . . . . . . 28

Subjects

Test Construction

Instrumentation

Pilot Studies

PROCEDURES. . . . . . . . . . . . .

Test Administrations

Test Environment

Materials

Recording of Responses

ANALYSIS OF DATA. . . . . . . . . . . 
IV RESULTS AND DISCUSSION • • • • • • • • • •

RESULTS . • • • • • • • • • • • • •

DISCUSSION • • • • • • • • • • • • • 46

V SUMMARY AND IMPLICATIONS • • • • • • • • • 55

SUMMARY . • • • • • • • • • • • . • 55

IMPLICATIONS • • . . • • . • • • 56

Clinical Implications

Research Implications

SELECTED BIBLIOGRAPHY . • • • • • • • • • • • • • • 59

APPENDICES • • • • • • • • • • • • • • • • • • • 66

APPENDIX A: SELECTED EXAMPLES OF NON-STANDARDIZED ASSESSMENT INSTRUMENTS UTILIZED IN IDENTIFYING CHILDREN WITH EXTREME LEARNING PROBLEMS AT EAST AND WEST GRESHAM GRADE SCHOOLS

APPENDIX B: PERMISSION REQUEST . • • • • • • • • 75

APPENDIX C: PPVT RAW SCORES • • . . • . • . . 76

APPENDIX D: COMMAND SERIES . • • • • • • • • • 77

APPENDIX E: RESPONSE RECORDING SHEET • • • • • • 79

APPENDIX F: PICTURES. • • • • • • • • • • • • . 81

APPENDIX G: INSTRUMENTATION SPECIFICATIONS . • • 87

APPENDIX H: TEST INSTRUCTIONS • • • • • • • • 88 


\section{LIST OF TABLES}

TABLE

PAGE

I Means, Standard Deviations, and $t$-Values for

all Subjects' Listening Scores in Quiet and in Noise. . . . . . . . . . . .

II Raw Scores for all Subjects' Listening Per-

formance in Quiet and in Noise and the

Difference between Those Scores. . . . .

II Means, Standard Deviations, and $t$-Values

for Normal and Reading Delayed Subjects. . 45

IV Means, Standard Deviations, and $t$-Values

for Normal and Reading Delayed Subjects

in Noise . . . . . . . . . . . . . 46 


\section{CHAPTER I}

\section{INTRODUCTION AND STATEMENT OF PURPOSE}

\section{INTRODUCTION}

Attention is crucial to learning, as demonstrated by researchers in psychology, psycholinguistics, speech and hearing science, and education. Before we can teach a child, according to Zigmond and Cicci (1968), we first must have his attention. Kent et al. (1972) stated only minimal learning can take place if the child does not attend, Broadbent (1958) stressed learning generally requires sustained attention, and Berry (1969) contended the ability to exclude irrelevant stimuli from the field of attention is basic to all learning. Children who have difficulty learning are often said to be those who do not seem to pay attention, particularly those who do not appear to listen.

Learning through listening is a natural process. Initially, the very young child acquires his basic ability to understand and to employ language as a mode of communication by hearing verbal models in his environment. Indeed, all areas of normal development are dependent principally upon normal auditory processing, as evidenced by the deaf and severely hard of hearing child's depressed educational achievement, personality development, and language and communication 
skills (Zigmond and Cicci, 1968).

By school age, the average child has developed the auditory skills upon which he must depend for efficient performance in the classroom. In these early school years, and throughout 1 ife as well, the chief learning mode is listening (Marsh, 1973; Early, 1971; and Zigmond and Cicci, 1968). Children not only spend the larger portion of the school day, especially in the primary grades, listening (Wilt, 1966), but they also tend to prefer gaining information through 1istening rather than reading (Zigmond and Cicci, 1968). Very often an integral part of that learning situation involves competing messages, with the intended message being susceptible to distraction from noise, music, or other speech (Chalfant and Flathouse, 1971; and Witkin, 1971). Environmental noise levels in elementary classrooms have been found to be higher than that in classrooms of older students (Nober, 1973; and Sanders, 1965). According to Chalfant and Flathouse (1971); to function satisfactorily in the classroom, the child must perform three basic auditory figure-ground tasks: 1) to distinguish familiar environmental sounds from general noise; 2) to select spoken language from environmental sounds; and 3) to select spoken words from a background of spoken language.

Auditory skills utilized in the classroom are refined and superimposed upon the secondary task of learning to read, for both speech perception and reading involve the processing 
of verbal language transmitted in a coded form (Sanders, 1977; Mattingly, 1972; and Zigmond and Cicci, 1968). Both listening and reading are currently regarded to be language processes, with difficulties in speech perception, in speech production, and in reading arising from errors in language coding (Sanders, 1977). Children with reading problems are often considered to have a primary language disorder involving a related symbol system, visual language (McGrady, 1968).

The exact role of attentional processes in visual language learning disabilities is being examined with increased interest. Although current theories and research are often conflicting, a substantial amount of evidence is accumulating to suggest the basic perceptual handicap among this population of school children is the inability to become alert and focus attention specifically on the information to be processed (Harris, 1976; Stubblefield and Young, 1975; Tarver. and Hallahan, 1974; Chalfant and Flathouse, 1971; Dykman et al., 1971; and McGrady and 01son, 1970).

The literature reveals little research on children's selective listening skills. Nearly all investigations reviewed by this writer have utilized earphones, a procedure which by its very nature helps focus the subject's attention on the task (Goldman et al., 1974). Few studies have explored children's ability to perform the three academically significant listening tasks proposed above by Chalfant and Flathouse. Only one study uncovered by this investigator, by Lasky and 
Tobin (1973), has investigated the effect of distracting noise on children's ability to carry out relatively complex commissions, a demand routinely required of children in the elementary classroom (Denhoff et a1., 1971; and Zigmond and Cicci, 1968). The present study sought to explore the effect of distracting auditory stimuli on children's ability to follow three-part unrelated commands.

\section{STATEMENT OF PURPOSE}

This study was undertaken to investigate the influence of distracting background noise on children's selective listening behavior. Reading delayed children were compared with children who were developing normally in acquiring reading skills. The specific questions the investigation sought to answer are:

1. When given instructions to perform a three-part command, will the accuracy of all subjects' responses be adversely affected by the presence of competing background noise?

2. Will the reading delayed children perform more poorly on the tasks under both conditions of quiet and noise?

3. Will background noise have a greater adverse effect on the reading delayed children?

\section{DEFINITION OF TERMS}

The following are operational definitions of specific terms employed in this investigation:

Attention: Selective activity producing a focus on a stimuIus, object, situation, or idea (Berry, 1969). 
Auditory Attention: The ability to direct and sustain attention to sounds (Oakland and Williams, 1971).

Selective Attention: One aspect of "auditory attention," involving the ability to select a relevant stimulus from a background of irrelevant stimuli and to continue attending selectively to this stimulus for an appropriate length of time (Oakland and Williams, 1971).

Dyslexia: A disorder manifested by difficulty in learning to read despite conventional instruction, adequate intelligence, and socio-cultural opportunity. It is dependent upon fundamental cognitive disabilities which are frequently of constitutional origin (Critchley, quoted by Boder, 1971).

Figure-Ground: A phenomenon occurring when a particular pattern stands out from the complex, forcing other pattern groupings to be perceived as background (Sanders, 1977).

Auditory Figure-Ground Perception: The ability to attend to one aspect of auditory input and to perceive it in relation to, but separate from, competing irrelevant sounds (Marsh, 1973).

Learning Disability: A child with learning disabilities is one with adequate mental abilities, sensory processes, and emotional stability who has a limited number of specific deficits in perceptive, integrative, or expressive processes which severely impair learning efficiency (Council for Exceptional Children, in Myklebust, Ed., 1971).

Listening: The composite process by which oral language communicated by some source is received, critically and purposefully attended to, recognized, and interpreted (or comprehended) in terms of past experiences and future expectancies (Petrie, 1966). 
CHAPTER I I

REVIEW OF THE LITERATURE

The present review of the literature concerning auditory. processing will be presented under four subtopical headings: History of Research in Auditory Processing; Theories of Auditory Perception and Attention; Attention and Learning; Listening, Language, and Reading.

HISTORY OF RESEARCH IN AUDITORY PROCESSING

The subject of perception and perceptual processing has been slow to capture the interest of researchers and educators. Initiated partly by the large numbers of men returning from the Second World War with neurological injuries and continued through successive wars in Korea and Vietnam, interest and knowledge has accumulated concerning perceptual processing in adults (Cruickshank, 1977).

Children's processing has been studied in connection with recent wide-spread interest in "learning disabilities," a. term descriptive of what Cruickshank (1977) believes to be neurophysiologically based disabilities related essentially to problems in perceptual processing.

Since the 1930's and $1940^{\prime} \mathrm{s}$, investigation of "learning disabled" children has concentrated on aspects of visual- 
perceptual processing, while other sensory modalities have received minimal attention from researchers (Cruickshank, 1977). Although the development of general academic readiness and communication skills are considered critically dependent upon adequate auditory abilities, their assessment and training has been a neglected area in education. According to Zigmond and Cicci (1968), the auditory development of children "has not been subject to the same type of careful observation and analysis as Gesell and others have given to visual, motor, and other learning tasks." Research data covering specific visual-perceptual behaviors necessary for school readiness are extensive (Marsh, 1973), while appraisal of the development of specific auditory parameters of language learning which appear to be necessary for reading are often overlooked (Greunewald and Pollak, 1973).

During the $1950^{\prime}$ 's auditory research gained momentum, particularly in the area of listening and attention. The volume of information, however, was sma1l. Compared to research in comparable fields (e.g., reading, speaking, etc.), listening research appeared "embryonic" (Kel1er, 1966). In 1949, Brown pointed out that the Third Mental Measurements Yearbook devoted seventy pages to available reading tests and none to tests of listening, a year later Anderson related a similar disparity in the number of studies on reading and listening (Keller, 1966), and in 1951 Brown observed 2600 research studies done in reading as compared to about twenty 
in 1 istening (Gold, 1973).

In Keller's (1966) survey of listening research during the fifties, he stated attention came to be taken for granted as a basic factor in listening, and detractors of training in listening, in fact, had frequently asserted listening was "just" attending. From this assumption were spawned studies examining "set" as an important psychological component of attention and listening.

Discussing attention and speech perception, Broadbent (1962) observed that despite the importance of attention to learning and various other cognitive activities, psychologists for many years had considered attention too nebulous in definition for empirical study. During the fifties, however, the concept of attention became more widely discussed and investigated. Concern was focused particularly on the efficiency of air traffic controllers at airports. Broadbent (1962) believed "a major cause of failure in these systems is that the human operator has too much information to handle simultaneously, or that he reacts to an unimportant signal when he should be dealing with an important one."

How the brain focuses attention on auditory information. remains mysterious. The applicability of a theory to account for the attentional behavior of both control tower operators and school children, learning disabled or otherwise, has engaged the minds of many contemporary researchers. 
THEORIES OF AUDITORY PERCEPTION AND ATTENTION

The perceptual process is complex. Neither vague definitions nor studies splintering to the many areas of the topic have helped to focus known information. One approach toward clarification has been taken by witkin (1971), who, in suggesting perception be distinguished from sensation and cognition, offered Gould's definition of perception as "...sensory experience which has gained meaning or significance. When, as the result of learning experiences, one understands the relationships of objects which were previously merely raw, undifferentiated sensory experiences, he is said to perceive these objects." Sensory reception, or sensation, comprises the first level of listening, and it is concerned primarily with the hearing acuity of the individual, while cognition, the third level, deals with the ability to comprehend and retain spoken language. Auditory perception, occupying an intermediate level between reception and cognition, involves, according to Witkin (1971), "...focus, attention, tracking, sorting, scanning, comparing, retreiving, and sequencing of spoken messages at the moment of utterance."

Although Witkin did not specify a sequential ordering of these processes, her placement of "focus" and "attention" at the beginning of the listing seems to agree with many other hypotheses about the series of interdependent stages involved in perception. A schematic model proposed by Solley and 
Murphy (Sanders, 1971) involves five successive stages: a) perceptual expectancy; b) attending; c) reception; d) trial and check; and e) final perceptual organization. The first component, "expectancy," is explained by Sanders (1971) to involve our ability to somewhat reliably predict the probability of a given stimulus complex occurring in a given situation. By developing such expectancies we are able to deal with the vast array of stimulation constantly assaulting our sense organs.

By expecting given stimuli, we deliberately search for them and so increase the probability of becoming aware of them. "Attention," the second component in Solley and Murphy's design, serves, therefore, to increase our chances of perceiving specific stimuli (Sanders, 1971).

The exact mechanism and neurophysiology of how attention is delivered is unknown. Attention is believed, however, to involve some sort of filtering-out of redundant information resulting in the sharp focus of the desired pattern (Sanders, 1977). First proposed by Broadbent (1958) in the now classical work Perception and Communication, the "Filter Theory" of attention serves as the basis of most thought on the subject since 1958. Maccoby and Konrad (1966) explained Broadbent's fundamental theory:

Broadbent holds that the human organism has limited, though great, capacity for handling information in a given time. Up to the point where his capacity is reached, an individual can "divide" attention.... Whenever the amount of information exceeds the individual's capacity, he must select only part of the 
available information. Broadbent holds that this selection is accomplished, to a large degree, centrally, through coding of incoming information...

More than one researcher has emphasized attention involves the organism's active selection, rather than passive reception, of stimuli. Berry (1969) described attention in psychological terms as "...the directive process that exerts a selective influence on perception and derives its direction from the motivation of the learner and the nature of the material to be learned." According to Sanders (1971), the human organism is incapable of remaining passive in the presence of a complex stimulus, and protects itself from being overwhelmed by available stimuli through the mechanism of selective processing. Active involvement is invariably evidenced in the form of discrimination, differentiation, and interpretation of the stimulus. Harris (1976) discussed Berlyne's findings that stimulus selection may be manipulated through operant conditioning. The distinction between "...involuntarily having one's attention caught and voluntarily paying attention..." (Moray, 1972) was believed by Moray (1972) to be both important and meaningful. Citing evidence from earlier dichotic listening experiments, Moray (1972) wrote that it may be shown that a listener can select one message and reject another simply by asking him to pay attention to one or the other.

Solley and Murphy (Sanders, 1977) considered the process of attending to be biological, involving a priority system 
within the organism which orders and "selects" the incoming stimuli. According to Sanders (1977), this concurs with Gibson's view that attention is "... a way of orienting the perceptual apparatus of the body." During the act of attention, neuronal activity is apparently specific to the focus of attention. Sanders (1977) quoted Brazier:

There is strong evidence that this descending inhibitory influence may play a role in "editing" the flow of information by acting to suppress some of the input from the periphery of the receptive field and thereby producing an effective inhibitory surround to the main focus.

The organization of stimuli through the process of selective attention results in the establishment of the figureground relationship, making it possible for the listener to attend to a particular sound source against a background of other noises and to shift attention from one sound source to another (Sanders, 1977). Sanders (1977) held that control of the figure-ground relationship, the preattentive processes, and the development of perceptual expectancies are all aspects of the same perceptual process.

Based on von Senden and Lawson's work with visual processes, the phenomenon of figure-ground perception appears to be an innate ability (Sanders, 1977). Hebb, too, contended that although much that is ascribed to perception may be a factor of learning, the ability to organize foreground and background is "...intrinsically primitive and independent of experience" (Lerea, 1961). Thus, control of the figureground relationship is the variable affecting the meaningful- 
ness of the selected stimulus, according to Sanders (1977). The degree of attention necessary to successfully perform the task depends upon the accuracy with which predictions can be made, and the accuracy, in turn, is determined by how strictly the individual is able to structure the task (Sanders, $1977)$.

\section{ATTENTION AND LEARNING}

The importance of the role of attention in learning may be underscored by the words of Penfield, cited by Dykman et al. (1971):

If I had another Iife to devote to human neurophysiology, I would like to devote it to the neuronal mechanism that makes possible the focussing of attention. Brain mechanisms develop only in the focussed light of conscious attention.... By selecting what he will attend to, the child conditions his own cortex... and with the help of parents and teacher, may be said to create his own mechanism.

Attention seems to be one of the critical conditions on which the analysis, integration, storage, and retrieval of information is based (Chalfant and Flathouse, 1971). Denhoff et a1. (1971) considered focus of attention and selection of appropriate cues from the background to be the foundation of skills and behavioral factors involved in information processing. Sustained attention, according to Broadbent (1958), is generally a requirement of learning.

Learning typically occurs amidst a constant din of sound and noise, more auditory (and visual) information than 
any child can appreciate at any one time. This environmental sound provides a means of continuously monitoring one's surroundings, though at a given time the child should consciously attend to and overtly respond to only a limited number of the sounds. If he is to function effectively, he must exclude many sounds outside the symbolic or communicative level (Siegenthaler and Barr, 1967). This requires attentional shifts from background to foreground auditory experiences, switching the focus of attention from one task to the next in a temporal or spatial order. Focus is changed either by: 1) performing several cognitive operations simultaneous1y, thus, splitting attention on more than one task or situation; or 2) choosing between two kinds of information, requiring focusing on one stimulus and ignoring another simultaneously presented signal (Chalfant and Flathouse, 1971). A child must learn on which signal to concentrate, but he cannot do this if he is unable to focus over a time period or span (Berry, 1969).

Attention to sounds becomes integrated with meaningful experience, and it largely provides the foundation for learning, especially language learning (Zigmond and Cicci, 1968). Enmeshed in the child's receptive and expressive language development is the formation of his concepts of the world and his mental capacities. Language, according to Zigmond and Cicci (1968), comes to reflect all aspects of the child's intellectual and social maturity. How the individual receives, 
organizes, and utilizes the morass of auditory stimuli in his environment will directly influence the level of language and learning he can attain (Zigmond and Cicci, 1968).

Upon entering school, the child is required not only to sustain 1istening for up to 158 minutes per day (Wilt, 1966), but he must continue to discriminate sounds, focus attention on the teacher's voice, and follow a series of directions in a classroom filled with other noises, e.g., pencils sharpened, desks and chairs shifted, sounds in the hall and outside the building, etc. (Zigmond and Cicci, 1968). Since about eighty percent of classroom interaction involves auditory input or auditory-visual integration, auditory perceptual skills are crucially important for learning to read, speak, spell, and use language (Vorobey, 1974; Katz, 1971).

Children mature at varying rates, thus, all children who experience learning problems do not have inadequate auditory processes. Nonetheless, moderate to severe auditory deficiencies are present in the preschool and primary grade histories of many children experiencing learning difficulties (Oakland and Williams, 1971). The possibility of a deficiency in one or more auditory abilities important for school success may be suggested by the following behaviors: symptoms of inattention (such as distractibility or listlessness), inadequate memory for words and numbers, paucity of 1 anguage, word substitutions, articulation disorders, difficulty in following directions, or difficulty in mastering basic reading skills 
(Perceptual Learning Systems, 1977; Katz, 1971; and Oak1and and Williams, 1971):

It is suspected that children displaying such symptoms of learning difficulties have a perceptual handicap underlying other learning skills. Dykman et al. (1971) stated many educators consider the ability to decode or decipher written and auditory messages critical to formal learning.

Children with learning disabilities have had probably at least as much practice as other children in deciphering the fragmented messages present in everyday speech, and, yet, according to Dykman et a1. (1971), they seem unable to compensate for their misperceptions. The more basic defect, they contended, is faulty attention, particularly becoming alert and focusing on important stimuli. Certain characteristics of learning disabled children suggest defective inhibition, their inability to ignore irrelevant information and their high degree of impulsivity (Harris, 1976; and Dykman et a1., 1971).

\section{LISTENING, LANGUAGE, AND READING}

Educators now recognize adequate auditory perceptual skills are essential to learning. If approximately seventyfive percent of what adults learn is derived from listening activities, as purported by Brown in 1950 (Oakland and Williams, 1971), then auditory processes must be at least equally important for infants, children, and adolescents. 
Of the many skills involved in auditory perception, many studies suggest one of the variables most important in listening and learning is auditory figure-ground perception (Marsh, 1973). No listening can take place without first focusing on and attending to the speech signal (Witkin, 1971), and, according to Sanders (1977), listening cannot occur in the absence of such selective attention.

Lerea (1961) believed figure-ground perception to be fundamental to all organized sensory behavior, and regards it as referent to the process of selectively abstracting certain salient sensations (figure) from the multitude of less relevant stimuli (ground), both impinging upon a sensory mechanism. In reviewing current findings regarding poor academic performances of the mild-to-moderate learning disabled, emotionally disturbed, and the mentally retarded child, Harris (1976) attributed the inability to select relevant stimuli, failure to attend to relevant stimulus dimensions, and short attention span as symptomatic of attentional deficits considered to be at least partly responsible for the pupils' learning difficulties.

The field of learning disabilities sprang from earlier work with brain-damaged children, and many of the behaviors attributed to the brain-damaged child are characteristic of those children presently being labeled "learning disabled" (Tarver and Hallahan, 1974; Dykman et al., 1971; and Johnson and Myklebust, 1967). In stating distractibility to be the 
main characteristic of brain-damaged children, Tarver and Hallahan (1974) quoted Cruickshank and Paul: "...hyperactivity, disinhibition, impulsivity, and perseveration may all be explained, to some extent, by the brain-injured child's distractibility, that is, his inability to filter-out extraneous stimuli and focus selectively on a task." Drawing from Clements, Harris (1976) stated attentional deficits common to both the brain-injured and the learning disabled child may support the hypothesis that the learning disabled child has similar, although minimal, cerebral damage. As previously mentioned, Dykman et al. (1971) have stressed the importance of attentional abilities, by proposing that problems in this area are the most significant determinant of learning disorder. Further evidence is provided by Lasky and Tobin (1973), whose findings suggest learning disabled students tended to be more easily distracted than controls by background noise, and the learning disabled children appeared to have more difficulty attending to relevant stimuli.

Reviewing findings on attentional deficits in children with learning disabilities, Tarver and Hallahan (1974) concluded these children were consistently found to be highly distractible. Lerea (1961) suggested auditory figure-ground perceptual disturbances are generally evident among brain injured individuals, and McGrady (1968) offered Williams' findings that aphasic children have demonstrated impaired auditory perception in the form of auditory figure-ground 
disturbances. According to Myklebust (1968) and Zigmond and Cicci (1968), impairment of the ability to select and comprehend foreground auditory stimuli and relate them to immediate scanning of remembered auditory experience for appropriate responses has direct bearing on later academic success.

Underlying every facet of the learning process is memory (Marsh, 1973; Zigmond and Cicci, 1968). When noise constantly interrupts the process of storing auditory information, frustration, failure, and learning gaps could ensue (Marsh, 1973). Chalfant and Flathouse (1971) stated that rehearsal, the repeating of information to oneself in order to remember it, is extremely vulnerable to interference. Apparently there is a high correlation between how easily a child may be distracted during rehearsal and the amount of attention he is devoting to the rehearsal task. According to the authors, deliberate rehearsal must take place in order for unfamiliar information to be retained, but little conscious effort is required for the child to remember information highly associated with material already learned. Marsh (1973) reported a study by Rabbitt in which it appeared the effort needed to recognize speech through noise may have interfered with other activities, such as, rehearsal necessary for efficient retention of data in the memory.

The ability to pay attention appears to be a developmental one. Hagen (1967) showed recall of task relevant material increased regularly with age among children in grades 
one, three, five, and seven. In a study of children aged eight, eleven, and fourteen years, the eleven year olds scored midway between the eight and fourteen year olds, clearly illustrating, according to the study's author, that older children were more skilled than younger ones at focusing attention on target material (Doyle, 1973). Attention and memory abilities appear, then, to increase with age during childhood, as documented by many sources (Smith et al., 1975; Doyle, 1973; Marsh, 1973; Hagen, 1967; Maccoby and Konrad, 1966; and Maccoby and Hagen, 1965). Hagen and Hale (1975) stated children's selective attention skills do not simply emerge passively, but rather, these skills are used actively as the child matures. Although Hagen (1967) believed the reason for improvement far from established, research within the last decade appears to offer tenable suggestions.

Drawing from audiological literature, an article by Siegenthaler and Barr (1967) documented known evidence of the improvement of hearing acuity with age. It is their contention that factors which account for increased auditory acuity may account also for changes in other auditory functions. They offered not increased sensitivity of the end organ of hearing itself, but three other factors which are a function of age: increased experience with auditory stimuli, practice in attending, and more complete nervous system development. Sanders (1977) cited Hagen and Hale in proposing the child's increasingly active participation in the attentional 
process develops his attentional skills. It is their opinion that some cognitive problems arise from the development of inadequate "attentional strategies." Smith et al. (1975) believed the younger child exhibits not a specific inability to perceive two distinct messages, but rather an inability to select between them.

Maccoby and Hagen (1965) postulated that the young child's handicap in focusing attention selectively is based on a lack of previously established discriminations between task-relevant and task-irrelevant aspects of the stimulus. They cited numerous writers who have emphasized the diffuse, undifferentiated quality of children's perceptions, concluding that in carrying out a task, the young child presumably takes in more information than he needs because his perception is too global.

According to more than one source, auditory attention to speech is an aspect of language processing (Sanders, 1977; Marsh, 1973; Dykman et al., 1971; and Oakland and Williams, 1971). Difficulty in linguistically organizing the speech stimulus inhibits control of the appropriate figure-ground relationship, which, in turn, impedes holding attention. Competing environmental stimuli, therefore, often cause problems for children with learning disabilities because of difficulty in maintaining figure-ground relationships (Sanders, $1977)$.

In the opinion of Pronovost, Wakstein, and Wakstein 
(1966), the most significant factor contributing to the speech and language deficits of fourteen observed "autistic or atypical children" was overattention to stimuli irrelevant to their focus of attention.

Hypothesizing that the impaired ability of children with learning disability to ignore irrelevant information is due to inefficient devising of rules for data processing and classification of incoming information, Dykman et a1. (1971) proposed inhibition to be controlled by speech mechanisms. Citing both Luria's and their own earlier belief that verbal mediators play a critical role in controlling autonomic responses and arousal, the authors quoted from their earlier work:

We assume that as a child matures, not only does egocentric (outer) speech disappear but that inner speech progressively condenses into single words or fragments of words (symbolic equivalents) which accomplish in thought what sentences and phrases accomplished earlier. Condensation helps the child to think rapidly, and a child whose inner speech is well developed should be able to process information more rapidly and react more quickly than a child who is slow in this development. Moreover, highly evolved inner speech with its rich language symbols, many of which are not communicable, would appear to be the "mechanisms" nonpareil to regulate higher forms of inhibition and excitation, including arousal.

This view agrees with the literature suggesting interference with "rehearsal," presumably enacted through "inner speech," may account, in part, for reduced performance in the presence of noise for language and learning disabled children.

Marsh's (1973) review of the literature stated an 
estimated seventy percent of the children with learning disabilities have associated speech and language problems, and McGrady (1968) related the greatest prevalence of learning disabilities are those involving language. An array of attentional deficits among language disordered children was mentioned by Berry (1969). Selective attention is frequently a weak skill in children with language-learning difficulties (Sanders, 1977), and, according to Thies and Thies (1977), scores on competing messages tasks significantly differentiate language-impaired children from normal children. Ironically, Sanders (1977) has observed, the deficit in Ianguage is at least a major contributing factor to this inattention. Anticipating appropriate language forms in the complex wave reduces the necessity of close attention to it, and the inability to focus on a desired stimulus leads to inconsistency of response to sound and difficulty in sustained 1 is tening.

General language development is wide1y agreed to underlie reading, an associated and more extensively researched area of learning (Sanders, 1977; Kinsbourne, 1975; Mattingly, 1972; 01iphant, 1972; Oakland and Williams, 1971; Kinsbourne, 1970; Fry et al., 1970; McGrady, 1968; and Zigmond and Cicci, 1968). According to Fries, learning to read involves transferring the auditory signs for language signals, which the child has already learned, to the new visual signs for the same signals (Sanders, 1977). Barr (1972) cited Rosner and 
Simon in referring to reading as primarily an auditorily based skill. While speech is a primary linguistic activity, reading is a secondary activity grafted onto the primary linguistic code (Mattingly, 1972). Hence, reading relies heavily on the reader's familiarity with the primary linguistic code, usually acquired through auditory perception (Sanders, 1977). Since both speech perception and reading involve the process of verbal language transmitted in a coded form, Sanders (1977) advanced the idea there must be an equivalence between the two intake modes. In the opinion of McGrady (1968), a reading disorder should be classified not as a "pure dyslexia," but rather as a perceptual or aphasic problem, as reading disorders of a psychoneurological nature may be due to disorders of experience, of inner and receptive language. Explanations of speech and reading in terms of the acquisition of discrete auditory-visual auditory skills have recently been supplanted, according to Sanders (1977), by consideration of both 1 istening and reading as language processes. These skills appear basic to the child's ability to acquire and use appropriate "linguistic strategies." Linguistic awareness, defined by Mattingly (1972) as "...the ability to internalize the stimulus information and then to know and use the appropriate modes of processing...," sustains the ability to read. Accordingly, Rees (1973) stated the understanding of spoken language is dependent upon a knowledge of linguistic structure. From this approach, Stark (1975) 
proposed reading failure to be a language-based problem.

Problems in the processing of speech or written material may be considered, then, as difficulties or errors in 1 anguage coding (Sanders, 1977; and Mattingly, 1972). The relationship of auditory perception to reading is well established (Barr, 1972), as numerous studies of children with reading disabilities confirm. Katz (1971) referred to Zigmond's evidence suggesting all dyslexic children have auditory difficulties, and Brassard (Katz, 1971) found reading comprehension had a higher correlation with listening ability than with inte1ligence quotient or mental age among students in grades four, five, and six. Flowers (1977) presented findings that thirty percent of reading comprehension skills were dependent on listening abilities.

One possible explanation for the apparent connection between learning disabled children's poor auditory skills and their deficient reading ability was offerred by Senf and Freund1 (1971). They stated that since

...both learning disabled and culturally deprived children are heavily auditorily dependent...it is possible that this preference indicates that the retarded readers are stimulus bound, that their attention is captured by auditory stimulation. As a result, they may be unable to deploy sufficient attention to visual material when auditory stimulation is present.

Considering the accumulating evidence to link the discussed academic skills and their apparent disturbance in the presence of distracting noise, the paucity of studies investigating the interrelationships of these factors is curious. 
Furthermore, environmental noise leve1s in normal classrooms, particularly in the early grades, are surprisingly high. Both Nober (1973) and Sanders (1965) found an overall mean sound level in elementary classrooms to vary between 64 and 69 decibels. An investigation of the effects of such classroom noise on the auditory discrimination performance of normal and learning disabled children in conditions of quiet and in classroom noise revealed both groups performed more poorly in noise than in quiet, and the learning disabled children performed inferiorly to the normals in both conditions (Nober and Nober, 1975). In a study by Lasky and Tobin (1973), first grade children, normals and learning disabled, were required to perform common classroom verbal and written tasks in the presence of either white noise or linguistic distractors (readings of prose, social studies information, and arithmetic facts). No significant difference occurred between the two populations of children in either quiet or in the presence of white noise. When linguistic distractors were used, however, the performance of the learning disabled children deteriorated, while that of the normal children did not. Sanders (1977) indicated these findings suggest linguistic information appears to be processed differently from nonlinguistic. In another discussion of these findings, Hallahan (1975) observed, "...this study indicates...that auditory stimuli similar to those encountered in the classroom are most likely to affect the performance of learning disabled 
chilldren."

In summary, the literature reveals extraneous auditory stimuli frequently appears to interfere with an individual's ability to sustain adequate attention to a specified task. Learning disabled children, often characterized by impaired attending skills, appear to be particularly affected by the presence of specific interfering auditory stimuli. In light of this evidence, and considering the current educational trend toward the grouping of children into separate and simultaneous activity centers during learning activities in classrooms, reading classes, and speech and language classes, study of the interrelationships among selected factors is indicated. 
CHAPTER III

METHODS AND PROCEDURES

METHODS

$\underline{\text { Subjects }}$

Subjects for this study were twelve white, first grade children, nine girls and three boys, ranging in age from 6.8 years to 7.7 years with an approximate mean age of seven years. A11 were students in a year-round school system at East Gresham and West Gresham Grade Schools, Gresham, Oregon. The six children comprising the control group for this study were selected at random from children not enrolled in any type of special education program.

The six children comprising the experimental group were enrolled in their school's Extreme Learning Problems (ELP) program where they received remedial reading services. Referred to in this study as "reading delayed," these children were enrolled in the ELP program based on a combination of the following:

1. Classroom teacher referral.

2. The ELP specialist's subjective judgement of each child's ability based on an informal, nonstandardized assessment of the following:
a) isolated sound recognition;
b) oral sound- 
blending skills; c) oral and written spelling level; d) unphonetic sight words for reading (from the Dolch Basic Word List); e) word recognition; f) informal reading inventory for independent, instructional, and frustration levels in word recognition and comprehension. (See Appendix A for selected examples of assessment instruments.)

3. The Beery test of visual discrimination and visual-motor coordination.

4. The Mann-Suiter screening for auditory discrimination and auditory memory.

5. The Metropolitan Readiness Test, which assesses skills involving: word meaning; listening; matching visual symbols; alphabet (letter names); number concepts, and copying shapes, letters, and numbers .

6. The Daberon Screening Device for School Readiness, a tool which assesses skills involving: body parts, color concepts, prepositions, following directions, plurals, general knowledge, visual perception, gross motor development, and categories.

Children scoring generally six months or more below grade or age level on specific tasks or combinations of tasks were considered eligible to receive ELP services. Test scores for 
the individual children participating in the present study were not available to this investigator.

Subjects were selected with no preference to sex.

Each child selected met the following criteria for inclusion in the study:

1. Received permission from parent(s) or guardian(s) to participate in the study. (See Permission Form, Appendix B.)

2. Displayed no known physical handicap, including uncorrected vision, as reported by the classroom teacher and/or school health records.

3. Had at least nine months of schooling.

4. Passed the audiometric screening test administered by this examiner in a quiet setting by responding positively to two of three presentations at $25 \mathrm{~dB}$ for each of the tones $500 \mathrm{~Hz}, 1000 \mathrm{~Hz}, 2000 \mathrm{~Hz}$, and $4000 \mathrm{~Hz}$ bilaterally.

5. Obtained a receptive vocabulary score within twelve months, plus or minus, of chronological age on the Peabody Picture Vocabulary Test (PPVT), Form A. Raw scores ranged from 58 to 66. (See Appendix C for each child's raw score on the PPVT.) The test was administered by this examiner.

Test Construction

The series of twenty, three-part unrelated commands (see Appendix D) was compiled by this examiner from examples of commands constructed by Joan McMahon, Portland State University instructor in Speech and Hearing Sciences, and from commands found in Zigmond and Cicci (1968). Each command series con- 
tained the following parts: 1) one fine or gross motor action; 2) one action of pointing to something on a paper or to an area in the room; and 3) one action of drawing either a circle around or a line under an object pictured on a page of paper. The ordering of these three parts was varied in each series by regularly alternating parts 1,2 , and 3 described above. This same list of commands served as the Response Recording Sheet (see Appendix E).

To each three-part command there corresponded one page of paper on which was pictured six objects (see Appendix F). The objects pictured were selected on the basis of predicted familiarity to the children in the study, phonetic dissimilarity, and ease of illustration (Katz, 1971).

The commands were tape recorded for later presentation to the subjects. The examiner's own voice was used to record the commands.

Sample and test items were recorded according to the following procedures:

1. Two sample three-part commands were presented at the beginning of the test.

2. This investigator's "normal speaking rate" was utilized during the recording of commands.

3. Ten seconds of silence were recorded immediately following each series, during which the subject was expected to respond. Responses were not timed, however, and the recorder was stopped during testing, if necessary, until the 
subject completed his response.

A segment of a children's story, Hansel and Gretel,

was recorded to serve as distracting background noise.

Two separate tape recordings were made originally: the first recording consisted of the series of twenty, three-part commands, hereafter referred to as "Command Series." The second recording consisted of the Hansel and Gretel story.

These two recordings were then duplicated to form one master tape. The master recording consisted of two parts: 1) the Command Series; and 2) the simultaneous recording of the Command Series and the background story, Hansel and Gretel.

The voice of a female speech pathology graduate student, Deon Johnson Shope, was used to record the story.

Phonetic similarity of the competing messages (Command Series and background story) was not controlled.

Instrumentation

A Sony dynamic microphone, Model MTL F-96, and two Sony reel-to-reel tape recorders, Model TC-105A, were used for the original recording of the test items onto reel tapes. The

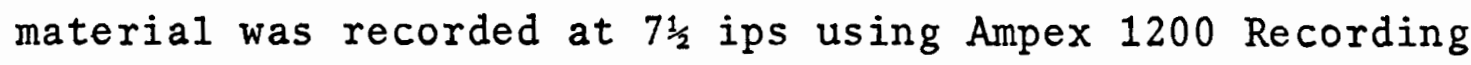
Tape. These two recordings were then duplicated on Ampex 1200 at $7 \frac{1}{2}$ ips using an Ampex Model AG-500 tape recorder to produce the master tape. An omnidirectional dynamic "Electro-Voice" microphone, Model RE15 was utilized.

Background noise was obtained by recording a live reading 
of the story, Hansel and Gretel. The voice of a female graduate student in speech pathology was used to record the story.

Ambient room noise in the testing environments at the two schools, and the intensity of tape presentation to the subjects, was measured with a General Radio, USA Model 1565-B Sound Level Meter, utilizing the C scale.

The audiometric screening of the subjects was completed using a Beltone portable audiometer, Model 10D.

A ree1-to-reel Sony tape recorder, Mode1 TC-105A, was used for administration of the listening test to all subjects. For further specifications on the instruments used in the study, see Instrument Specifications in Appendix G.

\section{Pilot Studies}

Two pilot studies were undertaken to determine whether the required task was within the range of an average first grade child's ability.

The first specific objective of the pilot study was to determine if the average first grade child could successfully discriminate signal (Command Series) from background noise (story) when both stimuli were delivered by the same voice. The literature states voices of different sexes are easiest to distinguish, two different voices of the same gender more difficult to distinguish, and two messages delivered by the same voice the most difficult (Sanders, 1965). Flowers (1977) utilized the same female voice in both directions and background 
story in a selective listening test he developed for use with five year old children, claiming voices of different person or gender too easy a discrimination task for children of that age. This investigator found no information on the complexity level of the directions, nor the signal-to-noise ratio utilized in the Flowers' study.

The second specific objective of the pilot study was to determine at what signal-to-noise ratio the average first grade child could successfully perform the listening task with about ninety percent accuracy. The signal-to-noise ratio in previous studies appears to vary between $0 \mathrm{~dB}$ and about $+15 \mathrm{~dB}$, the signal being of equal or greater intensity than the background. Lasky and Tobin (1973) utilized a $0 \mathrm{~dB}$ ratio (signal and noise equal) and $a+10 \mathrm{~dB}$ ratio (signal louder than noise); Marsh (1973) presented test words (signal) mixed with white noise (background) at the following three ratios: $40 / 38,40 / 34$, and $40 / 29$ decibe1s, the intensity of the signal exceeding the background in each instance.

Three subjects for the pilot study were selected at random from the pool of "normal" subjects. The test was recorded utilizing this investigator's voice for both the Command Series and background story, with the Command Series five decibels louder than the background.

Each of the three children in the first pilot study, then, was presented the listening test in which the signal-tonoise ratio was $65 / 60$ and both signal and background noise 
were delivered by the same voice. The children obtained the following scores: forty percent correct, ten percent correct, and zero percent correct. These findings suggested two messages delivered by the same voice were too difficult for first grade children to distinguish when the signal was five decibels louder than the background during the task required in this investigation.

A second recording was then made to be utilized in a second pilot study. The second recording utilized three signal- (Command Series) to-noise (background story) ratios: $65 / 60,65 / 55$, and $65 / 50$, differences of $5 \mathrm{~dB}, 10 \mathrm{~dB}$, and $15 \mathrm{~dB}$, respectively. The signal was louder than the background in each instance. In the second recording, the Command Series was delivered by the voice (female) of this examiner, and the background story was delivered by a different female voice.

The same three subjects participated in the second pilot study, which commenced the day following the first pilot study. The order in which the tests were administered was different for each of the three children. Each child was administered one version of the test each day, the testing being completed over a three day period. Two of the three children performed best (ninety percent and eighty-five percent) at the $65 / 55$ ratio. The third child performed best (sixty percent) at the $65 / 50$ ratio, with that subject's middle performance (fifty percent) at the $65 / 55$ ratio. For 
all three subjects, their worst performance (eighty percent, seventy percent, and forty-five percent) was at the $65 / 60$ ratio. From these results it was determined the $65 / 55$ ratio (difference of ten decibels) seemed within the range of the average first grade child's ability.

Subjects participating in the two pilot studies were not included in the larger study population.

The background story was chosen on the basis of its assumed familiarity to first grade children, and its therefore predicted greater distracting influence.

\section{PROCEDURES}

Test Administration

Audiometric screening and administration of the PPVT were performed on the same day for each child, two to three days prior to the administration of the first Command Series.

After meeting the screening criteria, the six normal children (controls) were randomly divided into two groups, three children in each group. Similarly, the six reading delayed children (experimental group) were randomly divided into two groups, three children in each group.

Listening skills testing was performed according to the following schedule:

DAY 1: Control Group (a), $\mathrm{N}=3$ Experimental Group (a), $\mathrm{N}=3$ QUIET BACKGROUND

DAY 2: Control Group (b), $\mathrm{N}=3$ Experimental Group (b), $\mathrm{N}=3$

NOISY BACKGROUND 
DAY 3: Control Group (a) Experimental Group (a)

NOISY BACKGROUND

DAY 4: Control Group (b) Experimenta1 Group

QUIET BACKGROUND

One-half of the Control Group was instructed to perform the tasks, first in a quiet environment followed by performance of the same tasks in a noisy environment, in which the story played continuously in the background. The second half of the Control Group performed the tasks first in the noisy environment, then the quiet environment. The same procedures were followed for the two halves of the Experimental Group: one-half of the group performed first in quiet and then in noise; the second half of the group performed first in noise and then in quiet. Each subject's second day of task performance was separated from his first performance by one day.

Each child was tested individually. The examiner escorted each subject from his/her classroom to the testing room, engaging the subject in casual conversation during that time in order to establish rapport.

The examiner gave each child instructions explaining the task required (see Appendix H) .

This examiner then played the two sample items. The background story/Command Series recording was played when testing a subject in the group to perform first in the noise conditions. If the subject performed incorrectly on one or both of the sample items, the examiner stopped the tape, 
reinstructed, and continued the tape. The tape was not stopped again unless the subject failed to perform three consecutive, three-part commands within the ten-second interval allotted on the tape. Positive reinforcement was provided by the examiner at the completion of the tenth task, with the words, "You're doing fine." At the end of the test each subject was told, "Thank you, you did a good job."

The examiner played the recorded Command Series, the same 1 ist being presented in the same order to all children. The Command Series recording was operated by turning the recorder on.

For each three-part command, the child was presented with one piece of paper picturing six objects (see Appendix F). Each recorded command requested the subject to interact with either one, or two, of the pictures on each page. Immediately following the subject's performance of a task series (all three parts of the commands), the top sheet of the twenty papers in front of the child was removed by the examiner, exposing the paper to be utilized in the next task.

Questions or remarks concerning the background noise or other aspect of the testing situation were ignored by the examiner.

Due to relatively high ambient noise levels in the testing rooms, all commands were presented at an intensity level slightly louder than that level regarded as normal speech, $60 \mathrm{~dB}$ (Newby, 1958). The volume of the recording 
was preset with a sound level meter monitoring prior to testing. The background story was presented at $10 \mathrm{~dB}$ lower intensity than the commands, as prerecorded on the tape.

Test Environment

Administration of the audiometric screening, the PPVT, and Command Series were performed in a conference room adjoining the school's library at East Gresham School. The room contained miscellaneous library supplies, one rectangular table, three chairs, and the testing equipment. The ambient noise level in the room ranged from 50 to $55 \mathrm{~dB}$. The volume of the recording was set at a decibel level of $65 / 55$, with the Command Series alone being presented at $65 \mathrm{~dB}$, and the Command Series/background story combination being presented at a $65 / 55 \mathrm{~dB}$ ratio, the Command Series being ten decibels louder than the background story.

At West Gresham School all testing was performed in the room usually used by the speech pathologist. The room contained miscellaneous speech supplies, one rectangular table, three chairs, and the testing equipment. The ambient noise level varied between 55 and $70 \mathrm{~dB}$, generally ranging from 60 to $65 \mathrm{~dB}$. Because of the interfering noise, the volume of the recording was increased, set at a decibel level of $70 / 60$.

At each school the child and the examiner sat at right angles to each other, with the child to the examiner's left. The tape recorder playing the commands or the commands/story combination was placed directly across the table from the 
subject, on a chair below his view, and to the examiner's right. Recording forms and lists of subjects were placed on the floor to the examiner's right.

\section{Materials}

Materials used in presenting the listening tasks included one Sony reel-to-reel tape recorder, a sound level meter, and a response recording sheet. To perform the tasks requested, each subject was presented with one box of eight colored pencils and a stack of twenty papers. Each child was instructed to choose one colored pencil. The twenty pages consisted of five different pages, each presented in the same order four times. On each page were pictures of six different objects (see Appendix F).

\section{Recording of Responses}

The examiner recorded each subject's responses using a pencil and a recording sheet. Beside each set of commands, the examiner marked " $J$ " for correct commission of the complete three-part task, or a " $"$ " for incorrect performance. The omission of one or more parts of the tasks, the substitution or addition of a task or item not requested, and/or incorrect sequencing of the tasks were scored as incorrect. Each of the twenty three-part tasks was scored as entirely correct or entirely incorrect. 
ANALYSIS OF DATA

The t-test analyses, using the one-tailed distribution, were performed to make the following three comparisons: 1) all the children's performance in quiet conditions and their performance in noise; 2) the "normal" children's overall performance and the reading delayed children's overall performance in quiet and in noise; and 3) the "normal" children's performance in noise and the reading delayed children's performance in noise. Mean scores and standard deviations were determined for all children's performance in quiet conditions and for their performance in noise conditions, for the "normal" children's overall performance and for the reading delayed children's overall performance, and for the performance in noise conditions of both "normal" children and reading delayed children.

The .05 level of significance was used in the statistical analysis. 


\section{CHAPTER IV}

\section{RESULTS AND DISCUSSION}

\section{RESULTS}

The purpose of this study was to investigate the effects of distracting background noise on the 1istening performance of two groups of first grade children: a group of six "normal" children and a group of six reading delayed children. Each child was tested individually on his/her ability to follow a series of twenty, three-part commands under two conditions: 1) in quiet, and 2) in the presence of 1 inguistic distraction. The study sought to answer the three questions posed at the outset of this investigation. The questions and the results of the study follow.

The first experimental question was: When given instructions to perform a three-part command, will the accuracy of all subjects' responses be adversely affected by the presence of competing background noise? A one-tailed $\underline{t}$-test for related measures was used to determine if a significant difference occurred between the mean performance score of all subjects in quiet and the mean performance score of all subjects in conditions of noise. The mean, standard deviations, and $\underline{t}$-test results are presented in Table I. 
TABLE I

MEANS, STANDARD DEVIATIONS, AND $t$-VALUES FOR ALL SUBJECTS' LISTENING SCORES IN QUIET AND IN NOISE

\begin{tabular}{lrrr} 
& $\frac{\text { Quiet }}{11.33}$ & $\frac{\text { Noise }}{6.83}$ & $t$ \\
Mean & 11.33 & 6.83 & $5.610 *$ \\
S.D. & 5.33 & 5.06 & \\
\hline & *p<.05, d.f. 11 & &
\end{tabular}

A statistically significant difference was found at the .05 level between the performance of all subjects in quiet and their performance in noise. The difference between the groups' performance was found to be significant, in fact, at less than the .0005 level. Based on this finding, the hypothesis is supported, that is, that competing background noise adversely affects children's ability to perform a three-part command. More specifically, children demonstrate a very significant deterioration in their ability to follow three-part commands in the presence of competing linguistic stimuli.

Visual inspection of raw scores for all subjects in Table II reveals a difference between each child's performance in quiet and his performance in noise. All children in the study performed better in the quiet environment than in the noise environment. 


\section{TABLE II}

RAW SCORES FOR ALL SUBJECTS' LISTENING PERFORMANCE IN QUIET AND IN NOISE AND THE DIFFERENCE BETWEEN THOSE SCORES

\begin{tabular}{|c|c|c|c|c|c|c|c|}
\hline \multicolumn{2}{|c|}{ Subject } & \multicolumn{2}{|c|}{ Quiet } & \multicolumn{2}{|c|}{ Noise } & \multicolumn{2}{|c|}{ Difference } \\
\hline $\begin{array}{l}1 \\
2 \\
3 \\
4 \\
5 \\
6\end{array}$ & Normals & $\begin{array}{r}9 \\
3 \\
20 \\
14 \\
13 \\
19 \\
78\end{array}$ & Total & $\begin{array}{r}1 \\
1 \\
13 \\
9 \\
5 \\
18 \\
47\end{array}$ & Total & $\begin{array}{r}8 \\
2 \\
7 \\
5 \\
8 \\
1 \\
31\end{array}$ & Tota1 \\
\hline $\begin{array}{r}7 \\
8 \\
9 \\
10 \\
11 \\
12\end{array}$ & $\begin{array}{l}\text { Reading } \\
\text { Delayed }\end{array}$ & $\begin{array}{r}7 \\
7 \\
13 \\
15 \\
5 \\
11 \\
58\end{array}$ & Total & $\begin{array}{r}6 \\
4 \\
10 \\
8 \\
3 \\
4 \\
35\end{array}$ & Total & $\begin{array}{r}1 \\
3 \\
3 \\
7 \\
2 \\
\frac{7}{23}\end{array}$ & Total \\
\hline
\end{tabular}

The second experimental question was: Will the reading delayed children perform more poorly on the tasks under both conditions of quiet and noise? A one-tailed $\underline{t-t e s t}$ for independent means was used to determine the differences between the overall performance of the "normal" children and that of the reading delayed children. The means, standard deviations, and $\underline{t}$-test results are presented in Table III. No statistically significant difference was found at the .05 level between the performance of these two populations of children. Both "normal" and reading delayed children performed essentially the same. Hence, reading delayed children did not 
TABLE III

MEANS, STANDARD DEVIATIONS, AND $t$-VALUES FOR NORMAL AND READING DELAYED SUBJECTS

Normals

10.416

6.84
Reading Delayed

7.75
S.D.

Me an

S.

$$
p>.05, d . f .22
$$

demonstrate significantly more difficulty following threepart directions in quiet or in noise than did the "normal" children.

The third experimental question was: Will background noise have a greater adverse effect on the reading delayed children? A one-tailed $t$-test for independent means was used to determine if a significant difference occurred between the mean performance score of "normal" subjects and of reading delayed subjects while both were in a noise environment. The means, standard deviations and $\underline{t}$-test results are presented in Table IV. Here, again, it is to be noted no statistically significant difference was found at the .05 level between "normal" children and reading delayed children in their ability to follow three-part directions in noise conditions. Reading delayed children did not demonstrate significantly more difficulty, then, following directions in noise than did "normal" subjects in the same conditions. 
TABLE IV

MEANS, STANDARD DEVIATIONS, AND t-VALUES FOR NORMAL AND READING DELAYED SUBJECTS IN NOISE

\begin{tabular}{lccc}
\hline & Norma1s & Reading Delayed & $\underline{t}$ \\
\hline Mean & 7.83 & 5.83 & .667 \\
S.D. & 4.60 & 1.83 & \\
\hline & $\mathrm{p}>.05$, d.f. 10 & &
\end{tabular}

\section{DISCUSSION}

As appears to be common among investigations of auditory skills, the results of this study seem to be somewhat unique unto themselves; they neither entirely support nor refute earlier findings.

Although the stimulus was dissimilar, the results of the first question posed in this study partially support the findings of Nober and Nober (1975) in their investigation of auditory discrimination skills under conditions of quiet and of "classroom noise." When the Wepman Auditory Discrimination Test was administered under these two conditions, Nober and Nober (1975) found both normal and learning disabled students performed more poorly in noise than in quiet. Both "normal" and reading delayed children in the present study also performed more poorly in conditions of noise.

It is unknown whether findings exploring one auditory skill, such as auditory discrimination, may be compared with 
results of investigations into another auditory skill, such as selective 1 istening. Indeed, it is unknown to what degree the selective listening task in the present study involved auditory discrimination skills. According to Sanders (1965), however, noise does not interfere with intelligibility of speech until it is $10 \mathrm{~dB}$ (sensation level) above the level of speech. The present study utilized background noise presented $10 \mathrm{~dB}$ below the level of speech. It seems unlikely, then, that auditory discrimination was a significant factor in the task required in the present study.

Other than the comparison with auditory discrimination abilities discussed above, the present study appears to refute al1 earlier studies discussed by this investigator. Again, examining results of question one, the present study found "normal" subjects as we11 as learning disabled subjects were adversely affected by noise. Lasky and Tobin (1973) found only the learning disabled students' performance diminished under conditions of noise, while the normal subjects' performance was unaffected. The present investigation does not corroborate Lasky and Tobin's (1973) findings.

Closer inspection of the raw data displayed in Table II suggests several implications regarding the listening performance of the two study populations and of individuals within those two groups. First, although every individual's score in quiet conditions exceeded his score in noise, a total of four subjects (Subject 2, Subject 6, Subject 7, and 
Subject 11) achieved scores differing by merely one or two points. Such a small difference seems to indicate these subjects, comprising one-third of the study population, tended to be only very minimally distracted, whereas the remaining two-thirds of the study population evidenced a greater degree of distraction, their quiet scores exceeding their noise scores by three to eight points.

According to test scores as viewed in Table II, the reading delayed subjects represent a more homogeneous group; compared with "normal" subjects, the reading delayed subjects' scores reflect a narrower range of ability. A difference of seventeen points was found between the "normal" group's highest score (20 points, Subject 3 ) and lowest score ( 3 points, Subject 2) in conditions of quiet, compared with a range of ten points between the highest score (15 points, Subject 10) and the lowest score ( 5 points, Subject 11 ) in quiet for the reading delayed group. Similarly, in conditions of noise the "normal" population demonstrated a difference of seventeen points between the highest (18 points, Subject 6) and the lowest scores ( 1 point, Subjects 1 and 2 ), while the reading delayed population's range between the highest score (10 points, Subject 9) and the lowest score ( 3 points, Subject 11) was seven points. Additionally, both the highest score (20 points, Subject 3 ) and the lowest score (3 points, Subject 2) among the "normal" population in conditions of quiet were higher and lower than the highest. (15 points, Subject 10) and 
lowest ( 5 points, Subject 5) scores in quiet for reading delayed subjects. Similarly, in noise conditions the "normal" groups' highest score (18 points, Subject 6) and lowest score ( 1 point, Subjects 1 and 2) were again higher and lower than the reading delayed subjects' highest (10 points, Subject 9) and lowest scores ( 3 points, Subject 11) in noise. Overall, the reading delayed children displayed a smaller discrepancy in scores between quiet and noise conditions than did "normal" subjects; as a group the experimental subjects seemed somewhat less affected by the presence of noise than were the "normal" subjects. One wonders if this smaller differential in the quiet versus noise performances of the reading delayed group was perhaps a function of their generally poorer 1istening performance even in the better (quiet) of the two listening situations; because their best total performance (58 points in quiet) was inferior to the "normal" subjects best total performance ( 78 points in quiet), the reading delayed subjects' range of ability was decreased perhaps because of an overall depressed performance level when compared with "normal" children.

In small sample studies, such as the present investigation, one must look at the performance of individual subjects within the study population. For this reason, it is to be noted that all but one of the twelve subjects in this study appeared, to this examiner, to willingly enter into and remain in the testing situation. The reader's attention is 
drawn, however, to Control Subject 2 (Quiet 3, Noise 1), who demonstrated to this investigator an apparent lack of interest and motivation in performing the task required.

The results of the second and third questions posed in this study do not support the findings of earlier investigators (Nober and Nober, 1975; and Lasky and Tobin, 1973). Nober and Nober (1975) found that in conditions of both quiet and "classroom noise," the auditory discrimination performance of learning disabled subjects was inferior to the normal subjects' performance; Lasky and Tobin (1973) found that in quiet, both normal and learning disabled subjects performed the same, but in noise conditions (1inguistic distraction) only the learning disabled subjects' ability to perform specified tasks was impaired, while the performance of the normal subjects was unaffected. In answering the second question, this study's results revealed the reading delayed children performed essentially the same as "normal" children under both conditions. Although the raw scores in Table II reflect an overall lower performance level for reading delayed subjects in both quiet and noise conditions, statistically the difference between "normal" and reading delayed children was not significant. Thus, these present findings indicate there appears to be no significant relationship between reading delay, as defined in this study, and a decreased ability to follow directions. In answering the third question, the present findings indicate reading delayed 
children performed, essentially, no worse in the presence of noise than did the "normal" children.

The lack of a significant difference between "normal" and reading delayed subjects in the presence of noise was a surprising finding, considering the literature supporting this notion (Sanders, 1977; Lasky and Tobin, 1973; Barr, 1972; Katz, 1971; Oakland and Williams, 1971; Senf and Freund1, 1971; and Zigmond and Cicci, 1968). One possible explanation may be found in the developmental literature, as reviewed in Chapter II of this study. Possibly, first grade children, the age studied in the present investigation, are still in the early developmental stages of selective attention. Thus, "normal" and "learning disabled" children are possibly not yet differentiated in this ability, and neither group of children has yet developed adequate ability to screen out distracting auditory stimuli. Another explanation of the findings may lie in the criteria used for selection of the "normal" and "reading delayed" groups of children. Since criteria for inclusion in the study as part of either the "normal" or "reading delayed" group is considered by this investigator to have been lax, it is possible the children included in each group were not clearly differentiated in their ability, or lack of ability, to read adequately for their grade level.

In comparing the results of the present study with the findings from a limited number of previous investigations of 
selective attention in children, there arose several areas of uncertainty. The various investigators' criteria for determining "reading delay" or "learning disability" appears to be inconsistent. Because each study appears to have used criteria different from any other similar study, it could well be that the "learning disabled" group does, in fact, represent a different type of child in each study. Another significant variable is the type of linguistic stimuli utilized. Is the effect of an adult female voice reading a fairy tale, as in the present study, comparable to a child (sex unspecified) reading prose, social studies, and arithmetic facts (Lasky and Tobin, 1973), or comparable to pre-recorded "classroom noise" (Nober and Nober, 1975)? Additionally, all studies reviewed by this investigator, including the present study, did not use actual live classroom noise. The Nober and Nober (1975) study simulated the noise condition on a tape, then fed the tape recorded noise into a small test room. According to Sanders (1977), "...it is questionable whether this can be equated with live classroom acoustic conditions which may be more or less favorable to learning than a recording made in the same room." The same question may be raised regarding the relative effect on learning any auditory distraction has when it is heard in a small test room as compared to the actual classroom situation. The signal-to-noise ratio of $+10 \mathrm{~dB}$ (signal ten decibels louder than background) appears to be common to the present 
investigation and to the study of Lasky and Tobin (1973). The results obtained in both studies do not concur with Flowers' (1977) contention that even a three decibel increase of signal over noise for kindergarten children simplifies the task so much that "normal" and "problem" children could not be identified on the basis of their performance. No other specifics regarding the task flowers required nor the content of the distraction were available to this investigator. The signal-to-noise ratio was not clearly specified in the Nober and Nober (1975) study.

The complexity of the task required also appears to be a factor (Treisman, 1964) which may account for differing performance levels from study to study. The response mode also may be a factor. Transferring auditory stimuli to verbal output, as in the Nober and Nober (1975) study, probably requires abilities distinct from transferring auditory stimuli to a visual-motor output, as in the Lasky and Tobin (1973) study and in the present study.

The age of the children studied appears to be a crucial variable, particularly in light of the developmental literature (Smith et a1., 1975; Doyle, 1973; Marsh, 1973; Hagen, 1967; Maccoby and Konrad, 1966; and Maccoby and Hagen, 1965). Because both attention and memory abilities seem to increase with age, findings should be compared only to results of similar studies utilizing subjects of approximately the same age group. Both the present study and the Lasky and Tobin 
(1973) study utilized first grade children (mean age approximately seven years), while the Nober and Nober (1975) study utilized children in an age range of 9.0 to 11.8 years. Conclusions, therefore, regarding comparisons of subjects who differ in age from two to approximately four and one-half years should remain guarded.

In conclusion, despite the variables to be considered in any study of selective listening skills, one finding of this investigation seems clear. Linguistic background noise appears to be a significant deterrant to accurate performance of three-part directions by first grade children. 


\section{CHAPTER V}

\section{SUMMARY AND IMPLICATIONS}

\section{SUMMARY}

It seems understood that distracting background noise interferes with attention, concentration, and performance of a specified task. Surprisingly, little data exists to substantiate such a suspicion, particularly regarding children. Many classroom teachers, attempting to schedule and plan learning programs for both the "normal" child and the apparently learning disabled child, have expressed concern about noise levels within classrooms and the distracting effect noise seems to have on the attention and performance of some children. A seemingly large number of children appear to have particular difficulty following directions in the presence of competing background noise. There appeared to be a need, therefore, for more evidence clarifying the role of background noise on children's ability to carry out a relatively complex task. This study investigated the effect of distracting linguistic background noise on children's ability to perform three-part commands. A total of twelve first grade subjects, six "normal" and six reading delayed, were individually administered a series of twenty, threepart commands. Each child performed once in quiet and once 
in a noise environment, and the performances in those two conditions were compared.

The results of the study showed a significant difference $(\mathrm{p}<.0005)$ between following the directions in quiet and in noise, with all children's level of accuracy decreasing under conditions of noise. The difference (p.>.05) between "normal" subjects' and reading delayed subjects' performance levels was not significant in either quiet or in noise conditions. The presence of noise, then, appeared to interfere with both groups' performance equally.

\section{IMPLICATIONS}

\section{Clinical Implications}

Although conclusions based on the results of this study should remain guarded due to the small sample utilized, the present findings have clinical and educational implications relevant to the learning and listening environment of school children. As Lasky and Tobin (1973) observe, attempts to secure a school environment free of competing messages seems impractical; however, the findings of the present investigation, as well as the findings of Nober and Nober (1975) and Lasky and Tobin (1973) should stimulate further investigation of the effect of auditory distraction which may be present in some school classrooms, some "open classrooms," and in some environments in which several "learning centers" operate simultaneously. 
Lasky and Tobin (1973) suggest research seems indicated "to determine and better define what is an effective learning environment." The present study appears to support this suggestion. The use of white noise to mask existing background noise warrants investigation; current literature reveals white noise to have no significant effect on listening tasks (Lasky and Tobin, 1973; and Sanders, 1965). It may also be indicated that during presentation of new or difficult concepts, children should be in an environment free from competing linguistic stimuli (Lasky and Tobin, 1973).

\section{Research Implications}

As previously discussed in Chapter IV, under "Discussion" of Results, there are many unanswered questions remaining in the relatively unexplored field of children's auditory perceptual abilities. Results obtained by various researchers suggest to this investigator that further research is needed concerning the following variables:

1) Standard criteria for determining a "learning disabled" child must be established among researchers before discussions of "learning disabled" childrens' abilities and disabilities can become meaningful and purposeful.

2) The type of linguistic stimuli utilized appears important to the degree to which it is distracting. Currently it is undetermined whether material familiar or unfamiliar to children is most distracting; it is undetermined whether an adult voice or another child's voice is 
most distracting; and it is undetermined whether a conversational speaking voice, shouting, or whispering is most distracting.

From this research there also arose a need to study the comparative effects of overlapping words (as in the SSW, "Staggered Spondaic Words" test) or sentences (as in the SSI, "Synthetic Sentence Identification") as related to the effects of continuous discourse in the background. Again, the variables mentioned above concerning the content of the linguistic stimuli may influence the results obtained.

It is suggested any replication of this study should include subjects older than first grade, and reading disabled subjects should be selected on the basis of standardized test scores which clearly differentiate "reading disabled" from "normal" subjects. 
$\underline{S} \underline{E} \underline{L} \underline{E} \underline{\mathrm{C}} \underline{\mathrm{T}} \underline{\mathrm{E}} \underline{\mathrm{D}}$

$\underline{B} \underline{I} \underline{B} \underline{L} I \underline{O} \underline{\mathrm{G}} \underline{\mathrm{R}} \underline{\mathrm{A}} \underline{\mathrm{P}} \underline{\mathrm{H}} \underline{\mathrm{Y}}$ 


\section{SELECTED BIBLIOGRAPHY}

BARR, D.F., Auditory Perceptual Disorders, An Introduction. Springfield, Illinois: Charles C. Thomas (1972).

BERRY, M.F., Language Disorders of Children, The Bases and Diagnoses. Englewood Cliffs, New Jersey: PrenticeHa11 (1969).

BODER, E., Developmental Dyslexia: Prevailing Diagnostic Concepts and a New Diagnostic Approach. In Myklebust (Ed.), Progress in Learning Disorders, Vol. II. New York: Grune and Stratton (1971).

BROADBENT, D.E., Perception and Communication. Oxford: Pergamon Press (1958).

BROADBENT, D.E., Attention and the Perception of Speech. Scientific American, 206:4, 143-151 (1962).

CHALFANT, J.C. and FLATHOUSE, V.E., Auditory and Visual Learning. In Myklebust, H.R. (Ed.), Progress in Learning Disorders, Vol. II. New York: Grune and Stratton (1971).

CRUICKSHANK, W.M., Foreword. In Sanders, D.A., Auditory Perception of Speech, An Introduction to Principles and Problems. New Jersey: Prentice-Hall (1977).

DENHOFF, E., HAINSWORTH, P., and HAINSWORTH, M., Learning Disabilities and Early Childhood Education: An Information Processing Approach. In Myklebust, H.R. (Ed.), Progress in Learning Disabilities, Vol. II. New York: Grune and Stratton (1971).

DOYLE, A.B., Listening to Distraction: A Developmental Study of Selective Attention. Journal of Experimental Psychology, 15, 100-115 (1973).

DYKMAN, R.A., ACKERMAN, P.T., CLEMENTS, S.D., and PETERS, J.E., Specific Learning Disabilities: An Attentional Deficit Syndrome. In Myklebust, H.R. (Ed.), Progress in Learning Disabilities, Vo1. II. New York: Grune and Stratton (1971).

DUKER, S., Listening: Readings. New York: The Scarecrow Press (1966). 
EARLY, M.J., Developing Effective Listening Skills. In Duker, S., Teaching Listening in the Elementary School. New York: The Scarecrow Press (1971).

FLOWERS, A., Auditory Perception and Learning. Lecture presented during one day workshop, Eugene, Oregon, February 2; 1977.

FRY, M.A., JOHNSON, C.S., and MUEHL, S., Oral Language Production in Relation to Reading Achievement Among Select Second Graders. In Bakker, D.J. and Satz, P. (Eds.), Specific Reading Disability, Advances in Theory and Method. Rotterdam University Press (1970).

GOLD, Y., The Importance of Teaching Listening Skills. Reading Improvement, $10: 3,14-16$ (1973).

GOLDMAN, R., FRISTOE, M., and WOODCOCK, R.W., G-F-W Test of Auditory Discrimination Manual. Circle Pines, Minnesota: American, Guidance Service (1974).

GRUENEWALD, L.J. and POLLAK, S.A., The Speech Clinician's Role in Auditory Learning and Reading Readiness. Language, Speech and Hearing Services in Schools, IV:3, 120-126 (1973).

HAGEN, J.W., The Effect of Distraction on Selective Attention. Child Development, 38, 685:94 (1967).

HAGEN, J.W. and HALE, G.A., The Role of Attention in Perceptual and Cognitive Development. In Cruickshank, W.M. and Hallahan, D.P. (Eds.), Perceptual and Learning Disabilities in Children, Vol. 2. Syracuse, N.Y.: Syracuse University Press (1975).

HALLAHAN, D.P., Distractibility in the Learning-Disabled Child. In Cruickshank, W.M. and Hallahan, D.P. (Eds.), Perceptual and Learning Disabilities in Children,

Vo1.2. Syracuse, N.Y.: Syracuse University Press (1975).

HARRIS, L.P., Attention and Learning Disordered Children: A Review of Theory and Remediation. Journal of Learning Disabilities, $9: 2,47-57$ (1976).

JOHNSON, D.J. and MYKLEBUST, H.R., Learning Disabilities. New York: Grune and Stratton (1967).

KATZ, J., Teachers' Guide. Kindergarten Auditory Screening Test. Follett Educational Corporation (1971). 
KELLER, P.W., Major Findings on Listening in the Past Ten Years. In Duker, S., Listening: Readings. New York: The Scarecrow Press (1966).

KENT, L.R., KLEIN, D. , FALK, A., and GUENTHER, H., A Language Acquisition Program for the Retarded. In McLean, J.E., Yoder, D.E., and Schiefelbusch, R.L. (Eds.), Language Intervention with the Retarded. Baltimore: University Park Press (1972).

KINSBOURNE, M., Cerebral Dominance, Learning, and Cognition. In Myklebust, H.R. (Ed.), Progress in Learning Disabilities, Vol. III. New York: Grune and Stratton (1975).

KINSBOURNE, M., The Analysis of Learning Deficit with Special Reference to Selective Attention. In Bakker, D.J. and Satz, P. (Eds.), Specific Reading Disability, Advances in Theory and Method. Rotterdam University Press (1970).

LASKY, E.Z and TOBIN, H., Linguistic and Nonlinguistic Competing Message Effects. Journal of Learning Disabilities, 6, 243-250 (1973).

LEREA, L., An Investigation of Auditory Figure-Ground Perception. The Journal of Genetic Psychology, 98, 229-237 (1961).

MACCOBY, E.E. and HAGEN, J.W., Effects of Distraction Upon Central Versus Incidental Recall: Developmental

Trends. Journal of Experimental Child Psychology, 2, $280-289(1965)$.

MACCOBY, E.E. and KONRAD, K.W., Age Trends in Selective Listening. Journal of Experimental Child Psychology, $3,113-122(1966)$.

MARSH, D.H., Auditory Figure-Ground Ability in Children. The American Journa1 of Occupational Therapy, 27:5, $218-225(1973)$.

MATTINGLY, I.G., Reading, the Linguistic Process, and Linguistic Awareness. In Kavanagh, J.F. and Mattingly, I.G. (Eds.), Language by Ear and by Eye. Cambridge, Mass.: The M.I.T. Press (1972).

MCGRADY, H.J., Language Pathology and Learning Disabilities. In Myklebust, H.R. (Ed.), Progress in Learning Disabilities, Vo1. I. New York: Grune and Stratton (1968).

MCGRADY, H.J. and OLSON, D.A., Visual and Auditory Learning Processes in Normal Children and Children with Specific Learning Disabilities. Journal of Exceptional Children, $36,581-589$ (1970). 
MORAY, N., Listening and Attention. Baltimore: Penguin Books (1972).

MYKLEBUST, H.R., Progress in Learning Disabilities, Vol. II. New York: Grune and Stratton (1971).

MYKLEBUST, H.R., Learning Disabilities: Definition and Overview. In Myklebust, H.R. (Ed.), Progress in Learning

Disorders, Vol. I. New York: Grune and Stratton (1968).

NEWBY, H., Audiology. New York: Appleton-Century-Crofts $(1 9 5 8 \longdiv { \text { . } }$

NOBER, L.W., Auditory Discrimination and Classroom Noise. Reading Teacher, 27:3, 288-291 (1973).

NOBER, L.W. and NOBER, E.H., Auditory Discrimination of Learning Disabled Children in Quiet and Classroom Noise. Journal of Learning Disabilities, 8, 57-60 (1975) .

OAKLAND, T. and WILLIAMS, F.C., Auditory Perception, Diagnosis and Development for Language and Reading Abilities. Seattle, Washington: Special Child Publications (1971).

OLIPHANT, G., Auditory Perception and Reading Disability. Bulletin of The Orton Society, XXII, Reprint No. 43 (1972).

Perceptual Learning Systems (Pub.), Listening Skills in Learning, The Central Auditory Abilities Program. Dearborn, Michigan: Perceptual Learning Systems, P.0. Box 864, 48121 (1977).

PETRIE, C.R., What is Listening? In Duker, S., Listening: Readings. New York: The Scarecrow Press (1966).

PIPER, W. (Ed.), Hansel and Grete1. Tales from Storyland. New York: The Platt and Munk Co. (1955).

PRONOVOST, W., WAKSTEIN, M., and WAKSTEIN, D., A Longitudinal Study of the Speech Behavior and Language Comprehension of Fourteen Children Diagnosed Autistic or Atypical. Exceptional Child, September, 19-26 (1966).

REES, N.S., Auditory Processing Factors in Language Disorders: The View from Procrustes Bed. Journal of Speech and Hearing Disorders, 30, 304-315 (1973).

SANDERS, D.A., Auditory Perception of Speech, An Introduction to Principles and Problems. New Jersey: Prentice-Ha11 (1977). 
SANDERS, D.A., Aural Rehabilitation. New Jersey: PrenticeHall (1971).

SANDERS, D.A., Noise Conditions in Normal School Classrooms. Exceptional Child, 31, 344-353 (1965).

SENF, G.M. and FREUNDL, P.C., Memory and Attention Factors in Specific Learning Disabilities. Journal of Learning Disabilities, Vo1. 4, 94-106 (1971).

SIEGENTHALER, B. and BARR, C., Auditory Figure-Ground Perception in Norma1 Children. Child Development, 1163-67 (1967).

SMITH, L.B., KEMLER, D.G., and ARONFREED, J., Developmenta1 Trends in Voluntary Selective Attention: Differential Effects of Source Distinctness. Journal of Experimental Child Psychology, 20, 352-362 (1975). STARK, J., Reading Failure: A Language-Based Problem. ASHA,

STUBBLEFIELD, J.H. and YOUNG, C.E., Central Auditory Dysfunction in Learning Disabied Children. Journal of Learning Disabilities, $8: 2,32-37$ (1975)

TARVER, S.G. and HALLAHAN, D.P., Attention Deficits in Children with Learning Disabilities: A Review. Journal of Learning Disabilities, $7: 9$, 560-569 (1974)

THIES, T.L. and THIES, H.H., Responses to Distorted Speech and Competing Messages of Children with Severe Language Disorders. Abstract of paper, presented during workshop on Auditory Perception and Learning, by Flowers, A., in Eugene, Oregon, February 2, 1977.

TREISMAN, A.M., Verbal Cues, Language, and Meaning in Selective Attention. American Journal of Psychology, 77, 206-219 (1964).

VOROBEY, N., Learning to Listen and Respond is Difficult for Some Children. Fairfax Schools Bulletin, Fairfax County, Virginia Public Schools, 10:7 (1974).

WILT, M., Demands on the Listening Skills of Elementary School Children. In Duker, S., Listening: Readings. New York: The Scarecrow Press (1966).

WITKIN, R.B., Auditory Perception--Implications for Language Development, Language, Speech and Hearing in the Public Schools, $2: 4,31-52(1971)$. 
WYNN, R., Children Should Be Seen and Not Heard. In Duker, S., Teaching Listening in the Elementary School. Metuchen, N.J.: The Scarecrow Press (1971).

ZIGMOND, N.K. and CICCI, R., Auditory Learning. San Rafae1, California: Dimensions Publishing Co. (1968). 


$$
\text { A } \underline{P} \underline{P} \underline{E} \underline{N} \underline{D} \underline{I} \underline{C} \underline{E} \underline{S}
$$


APPENDIX A

SELECTED EXAMPLES OF NON-STANDARDIZED ASSESSMENT INSTRUMENTS UTILIZED IN IDENTIFYING CHILDREN WITH EXTREME LEARNING PROBLEMS AT EAST AND WEST GRESHAM GRADE SCHOOLS 
SOUND SHEET ONE

Name Date

a

S

$\overline{\mathrm{e}}$

f

d

$r$

i

th

c

○

$\mathrm{n}$

$t$

h

$\mathrm{u}$

g

1

w

sh

I

k

$\overline{0}$

v

$\mathrm{p}$

ch

e

b

$\widehat{\text { ing }}$

$\bar{i}$

y-

er

j

$x$

o

$-\bar{y}$

wh

$z$

qu-

$\overline{\mathrm{u}}$

Total 40 
LETTER NAMES

Name

Date

Total Score

$\begin{array}{llllllll}\text { A } & \text { B } & \text { C } & \text { D } & \text { F } & \text { K } & \text { P } & \text { U } \\ \text { G } & \text { L } & \text { Q } & \text { V } & \text { H } & \text { M } & \text { X } & \text { 0 } \\ \text { I } & \text { N } & \text { S } & \text { Y } & \text { E } & \text { J } & \text { T } & \text { Z } \\ \text { R } & \text { W } & & & & & & \end{array}$

Uppercase

q

W

e

$r$

$t$

y

$\mathrm{u}$

i

0

$\mathrm{p}$

a

g $\quad f$

s

d

h

$z$

1

k

j

$x$

c

b

n

m

Lowercase

26

Grand Total 
DO NOT USE

Name

Date

Score

$\begin{array}{lllllllllllll}\text { a } & b & c & d & e & f & g & h & i & j & k & 1 & m \\ n & \circ & p & q & r & s & t & u & v & w & x & y & z\end{array}$

Lowercase total score

1. Starting Point

2. Second and Third

stroke errors

3. Reversals

4. Need visual clues

5. Spacing problems

Handwriting Evaluation

Star the letter if made correctly

\section{6}

$\begin{array}{lllllllllllll}\text { A } & \text { B } & \text { C } & \text { D } & \text { E } & \text { F } & \text { G } & \text { H } & \text { I } & \text { J } & \text { K } & \text { L } & \text { M } \\ \text { N } & \text { O } & \text { P } & \text { Q } & \text { R } & \text { S } & \text { T } & \text { U } & \text { V } & \text { W } & \text { X } & \text { Y } & \text { Z }\end{array}$

Uppercase total score

Grand total 
AYERS ORAL Spelling Test

$\begin{array}{llll}\text { I-II } & \text { III-IV } & \frac{\nabla-V I}{\text { catch }} & \frac{V I-V I I I}{\text { often }} \\ \text { eat } & \text { black } & \text { afraid } & \text { stopped } \\ \text { sit } & \text { warm } & \text { uncle } & \text { motion } \\ \text { lot } & \text { unless } & \text { rather } & \text { theater } \\ \text { box } & \text { clothing } & \text { comfort } & \text { improvement } \\ \text { belong } & \text { began } & \text { elect } & \text { century } \\ \text { door } & \text { able } & \text { aboard } & \text { total } \\ \text { yes } & \text { gone } & \text { jail } & \text { mention } \\ \text { low } & \text { suit } & \text { shed } & \text { arrive } \\ \text { soft } & \text { track } & \text { retire } & \text { supply }\end{array}$

AYERS WRITTEN Spelling Test

$\begin{array}{llll}\text { I-II } & \text { III-IV } & \frac{\nabla-\nabla I}{\text { watch }} & \text { VI-VIII } \\ \text { how } & \text { dash } & \text { asist } \\ \text { stand } & \text { dash } & \text { remain } & \text { difference } \\ \text { bring } & \text { fell } & \text { direct } & \text { examination } \\ \text { teII } & \text { fight } & \text { appear } & \text { particular } \\ \text { baII } & \text { buy } & \text { liberty } & \text { affair } \\ \text { ask } & \text { stop } & \text { enough } & \text { course } \\ \text { way } & \text { walk } & \text { fact } & \text { neither } \\ \text { has } & \text { grant } & \text { September } & \text { local } \\ \text { baby } & \text { soap } & \text { station } & \text { marriage } \\ \text { ran } & \text { news } & \text { between } & \text { further }\end{array}$

Ayers Oral and Written Spelling Scores

\begin{tabular}{ccccc}
$\%$ & \multicolumn{1}{c}{} & 2.3 & 3.4 \\
0 & 1.0 & 1.6 & 2.6 & 3.8 \\
\hline 10 & 1.3 & 1.8 & 2.8 & 4.5 \\
\hline 20 & 1.5 & 2.0 & 3.1 & 4.7 \\
\hline 30 & 1.7 & 2.2 & 3.4 & 5.0 \\
\hline 40 & 1.8 & 2.5 & 3.7 & 5.3 \\
\hline 50 & 2.1 & 2.8 & 4.1 & 5.7 \\
\hline 60 & 2.3 & 3.1 & 4.6 & 6.3 \\
\hline 70 & 2.5 & 3.5 & 5.5 & 7.1 \\
\hline 80 & 2.7 & 4.0 & 6.5 & 8.5 \\
\hline 90 & 3.1 & 4.7 & 6
\end{tabular}

If get 5 or more correct in any column, you must go on to next colum (or else average in the o\% of correct number from that next column). Add $\%$ of correct scores and divide by number of columns.

e.g. 7 correct colum $I-I I=2.5$

5 correct colum III-IV $=2.8$ Add: 2.5 Divide:

3 correct column $\nabla-\nabla I=3.1$

$$
2.8=\text { score }
$$

2.8

$\begin{array}{lll}3.1 & 3 \longdiv { 8 4 } 2 . 8\end{array}$ 
NAME

TRACK

Directions to student: rab is a part of the word rabbit. You pronounce it 'rab.' Here are some parts of words. Pronounce them.

$\begin{array}{llllll}\text { ket } & \text { raze } & \text { gath } & \text { weet } & \text { jock } & \text { rile } \\ \text { jus } & \text { gan } & \text { quib } & \text { lobe } & \text { cad } & \text { mute } \\ \text { fam } & \text { pox } & \text { yel } & \text { chum } & \text { nish } & \text { cuv }\end{array}$

Blending skill comments:

Use of vowel patterns:

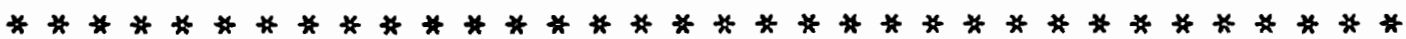

ONPHONETIC SIGHT WORDS

\begin{tabular}{|c|c|c|c|c|}
\hline $\begin{array}{l}\text { Preprimer } \\
2 \\
\text { come } \\
\text { one } \\
\text { said } \\
\text { the } \\
\text { to } \\
\text { two } \\
\frac{\text { where }}{8}\end{array}$ & $\begin{array}{l}\text { Primer } \\
\text { are } \\
\text { do } \\
\text { four } \\
\text { have } \\
\text { pretty } \\
\text { there } \\
\text { they } \\
\text { was } \\
\text { what } \\
\text { who } \\
10\end{array}$ & $\begin{array}{l}\text { Grade One } \\
\text { again } \\
\text { any } \\
\text { could } \\
\text { give } \\
\text { live } \\
\text { of } \\
\text { once } \\
\text { *put } \\
\text { some } \\
\text { were } \\
\text { walk } \\
\frac{\text { know }}{12}\end{array}$ & $\begin{array}{l}\text { Grade Two } \\
\text { been } \\
\text { buy } \\
\text { does } \\
\text { don't } \\
\text { many } \\
\text { *pull } \\
\text { their } \\
\text { very } \\
\text { would } \\
\text { your } \\
10\end{array}$ & $\begin{array}{l}\text { Grade Three } \\
\text { carry } \\
\text { done } \\
\text { *full } \\
\text { laugh } \\
\text { only } \\
\text { small } \\
\text { doesn't } \\
7\end{array}$ \\
\hline
\end{tabular}

Misc.

\begin{tabular}{ll}
\hline often & sure \\
floor & son \\
door & won \\
*push & from \\
move & build \\
goes & busy \\
gone & people \\
says & shoe \\
whose & laugh \\
whole & Wednesday \\
should & $\frac{1}{21}$
\end{tabular}

* 4 4 /00/

Total $=68$ 
Readings taken from McCracken, Glenn, and Walcutt, Charles C. Lippincott's Basic Reading. New York: J.B. Lippincott Company, 1971.

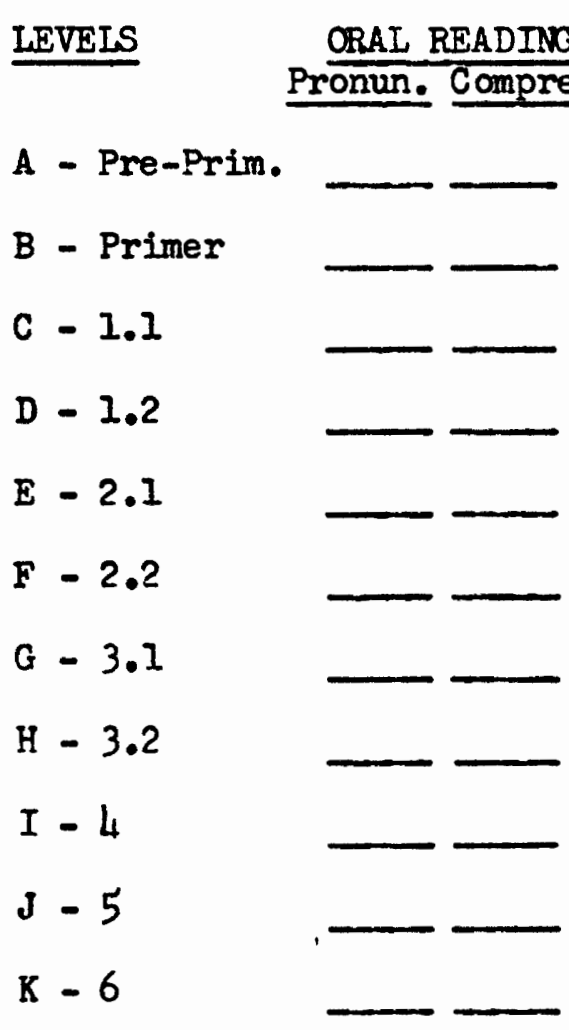

EST IMATED LEVELS

Independent

Instructional

Frustration

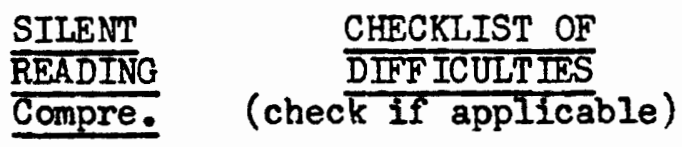

SILENT READING

Lip movements Whispering High rate at expense of mastery Head movements; marked Marked insecurity evident Poor attention

- Low rate of silent reading Other - Other

ORAL READING

Word-by-word
reading
Inadequate
- phrasing
Monotonous tone
- Poor enunciation
- Marked insecur-
- ity evident
Marked head
- movements
Easily distract.
- Uses finger or
- pointer
Holds book too
-lose
Loses place
- easily



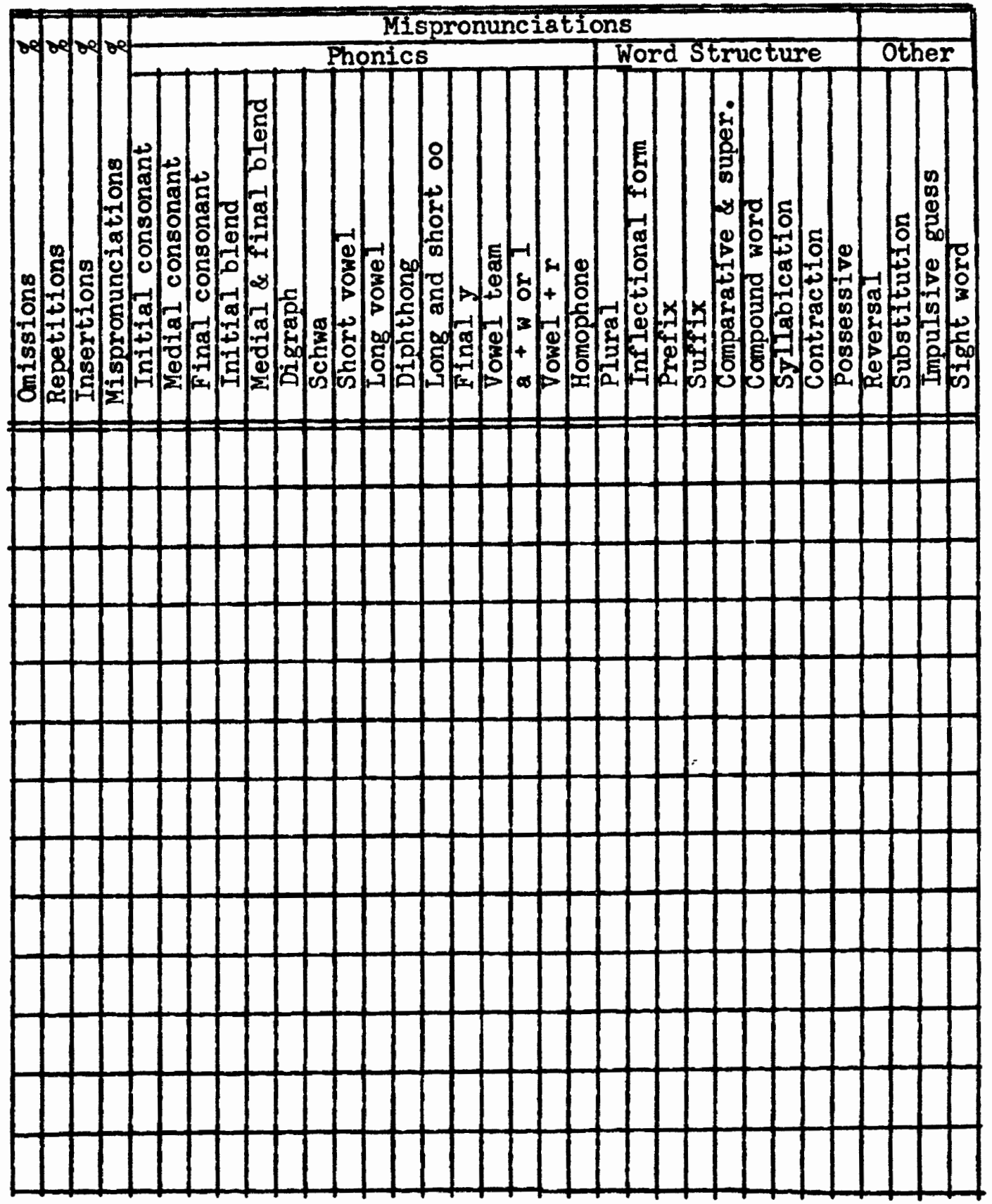


\section{APPENDIX B}

\section{PERMISSION REQUEST}

\section{Dear Parents:}

I am a graduate student in Speech and Hearing Science at Portland State University. Your child's school has given me permission to study the listening skills of first grade children. The study will help us understand how well first grade children: can "tune out" background noise and concentrate on one person's voice.

The children will listen to tape recorded instructions and then do what was instructed. An example is: "Stand up, clap your hands, sit down." The children will 1isten to the se instructions once when the room is quiet, and once when a tape recorded children's story is playing in the background. This will take about 15 minutes for each child. study.

No names will be used in the written results of the

Please help me by filling out the form below, and sending the signed form with your child back to his/her teacher as soon as possible.

Thank you,

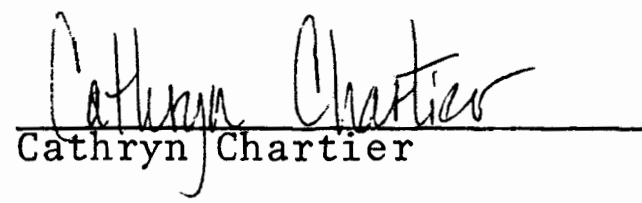

I give permission for my child, , to participate in the study being done by Cathryn Chartier in my child's school. 
APPENDIX C

PPVT RAW SCORES

Subjects

Raw Score

"Normal" Subjects

Subject 1

58

Subject 2

66

Subject 3

65

Subject 4

63

Subject 5

65

Subject 6

60

$\underline{\text { Reading Delayed Subjects }}$

Subject 7

62

Subject 8

64

Subject 9

58

Subject 10

62

Subject 11

59

Subject 12

62 


\section{APPENDIX D}

\section{COMMAND SERIES}

Sample A: Stand up

Clap your hands

Sit down

1. Shake your head

Point to the dog

Draw a line under the tree

2. Point to the ceiling

Draw a circle around the cat

Clap your hands

3. Make an " $X$ " on the boy

Stick out your tongue

Point to the telephone

4. Close your eyes

Point to the top of the page

Draw a line under the fish

5. Point to the mother

Draw a circle around the knife

Pat your stomach

6. Draw a line under the car

Scratch your head

point to the wagon

7. Put your hand over your mouth

Point to the bed

Make an " $X$ " on the ladder

8. Knock on the table

Draw a circle around the pig

Cross your legs

9. Draw a line under the bike

Point to the cookies

Wiggle your fingers

10. Point to hte house

Put your hands under your chair

Draw a circle around the hammer 
Sample B: Touch your nose

Point to your pencil

Make an " $X$ " on the paper

11. Touch your mouth

Make an " $X$ " on the banana

Point to the floor

12. Draw a line under the shirt

Look behind you

Touch your knee

13. Point to the boat

Swing your arms

Draw a line under the apple

14. Touch your shoulder

Draw a circle around the football

Point to the chair

15. Draw a line under the corn

Point to your elbow

Put your hands under your chin

16. Point to yourself

Stretch up high

Make an " $X$ " on the pants

17. Wink your eye

Draw a circle around the clown

Point to the scissors

18. Draw a line under the star

Point to your pencil

Stamp your foot

19. Point to the corner of the table

Touch your shoe

Make an " $X$ " on the lamp

20. Put your hands on your waist

Draw a circle around the frog

Turn the paper over 
APPENDIX E

RESPONSE RECORDING SHEET

Sample A: Stand up

$$
\begin{aligned}
& \text { Clap your hands } \\
& \text { Sit down }
\end{aligned}
$$

Name

Group Trial

- 1. Shake your head Point to the dog

Draw a line under the tree

- 2. Point to the ceiling

Draw a circle around the cat

Clap your hands

3. Make an " $X$ " on the boy

Stick out your tongue

Point to the telephone

- 4. Close your eyes

Point to the top of the page

Draw a line under the fish

5. Point to the mother

Draw a circle around the knife

Pat your stomach

- 6. Draw a line under the car

Scratch your head

Point to the wagon

- 7. Put your hand over your mouth

Point to the bed

Make an " $X$ " on the ladder

8. Knock on the table

Draw a circle around the pig

Cross your legs

9. Draw a line under the bike

Point to the cookies

Wiggle your fingers

10. Point to the house

Put your hands under your chair

Draw a circle around the hammer 
Name

Group

Trial

Sample B: Touch your nose

Point to your pencil

Make an " $X$ " on the paper

11. Touch your mouth

Make an " $X$ " on the banana

Point to the floor

12. Draw a line under the shirt

Look behind you

Touch your knee

13. Point to the boat

Swing your arms

Draw a line under the apple

14. Touch your shoulder

Draw a circle around the football

Point to the chair

15. Draw a line under the corn

Point to your elbow

Put your hands under your chin

16. Point to yourself

Stretch up high

Make an " $X$ " on the pants

17. Wink your eye

Draw a circle around the clown

Point to the scissors

18. Draw a line under the star

Point to your pencil

Stamp your foot

19. Point to the corner of the table

Touch your shoe

Make an "X" on the lamp

20. Put your hands on your waist

Draw a circle around the frog

Turn the paper over 
APPENDIX F

PICTURES 

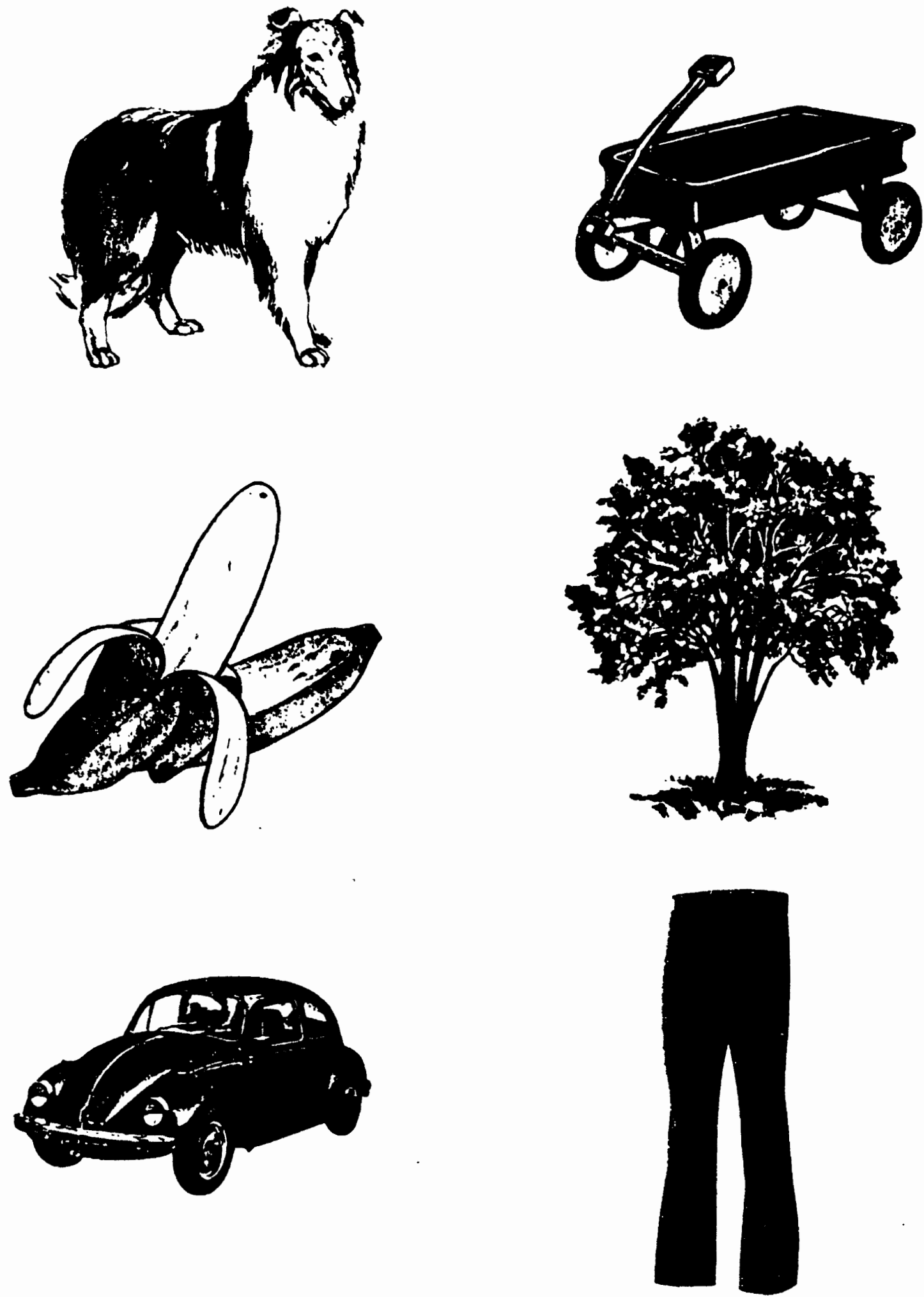
0

o

成 

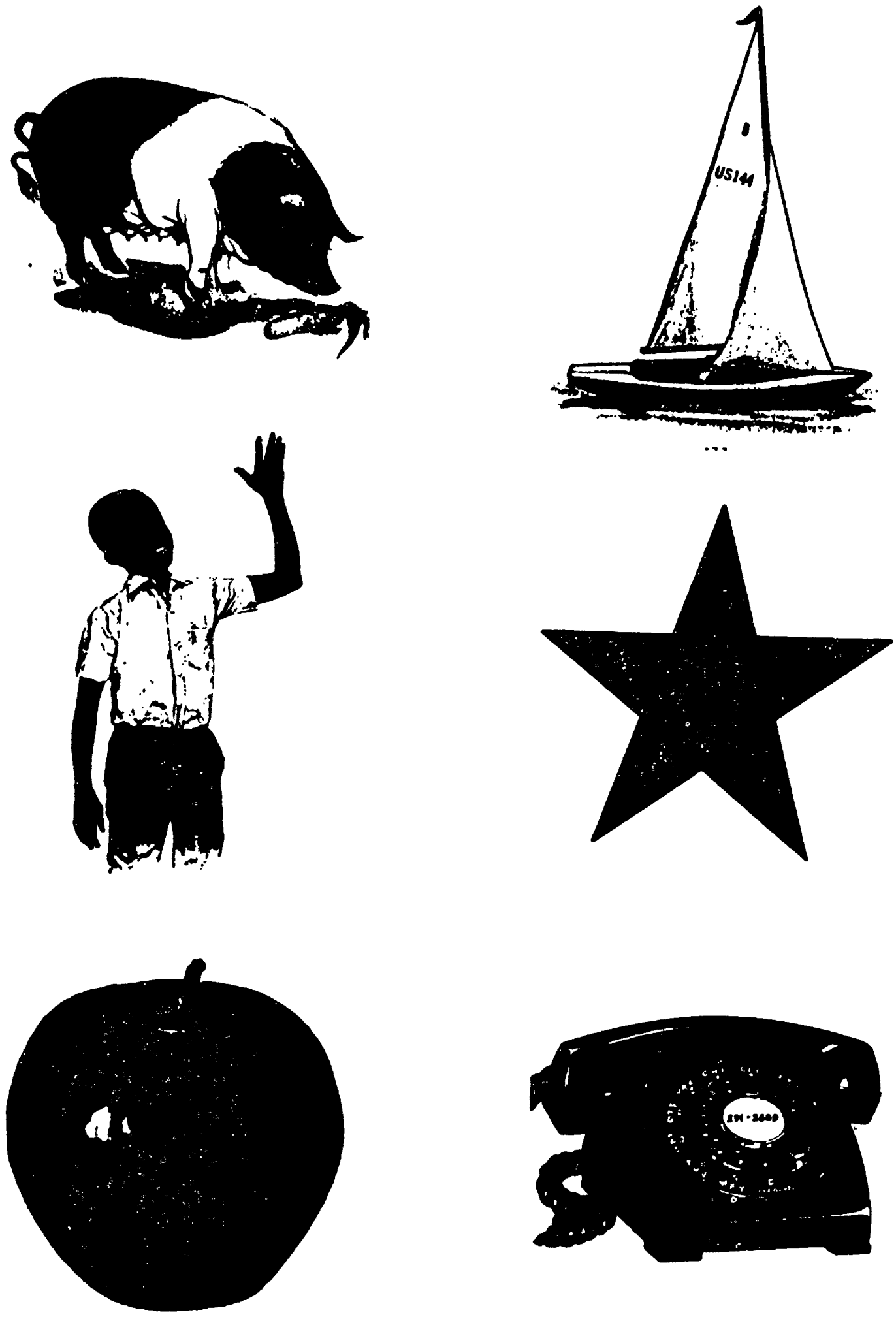

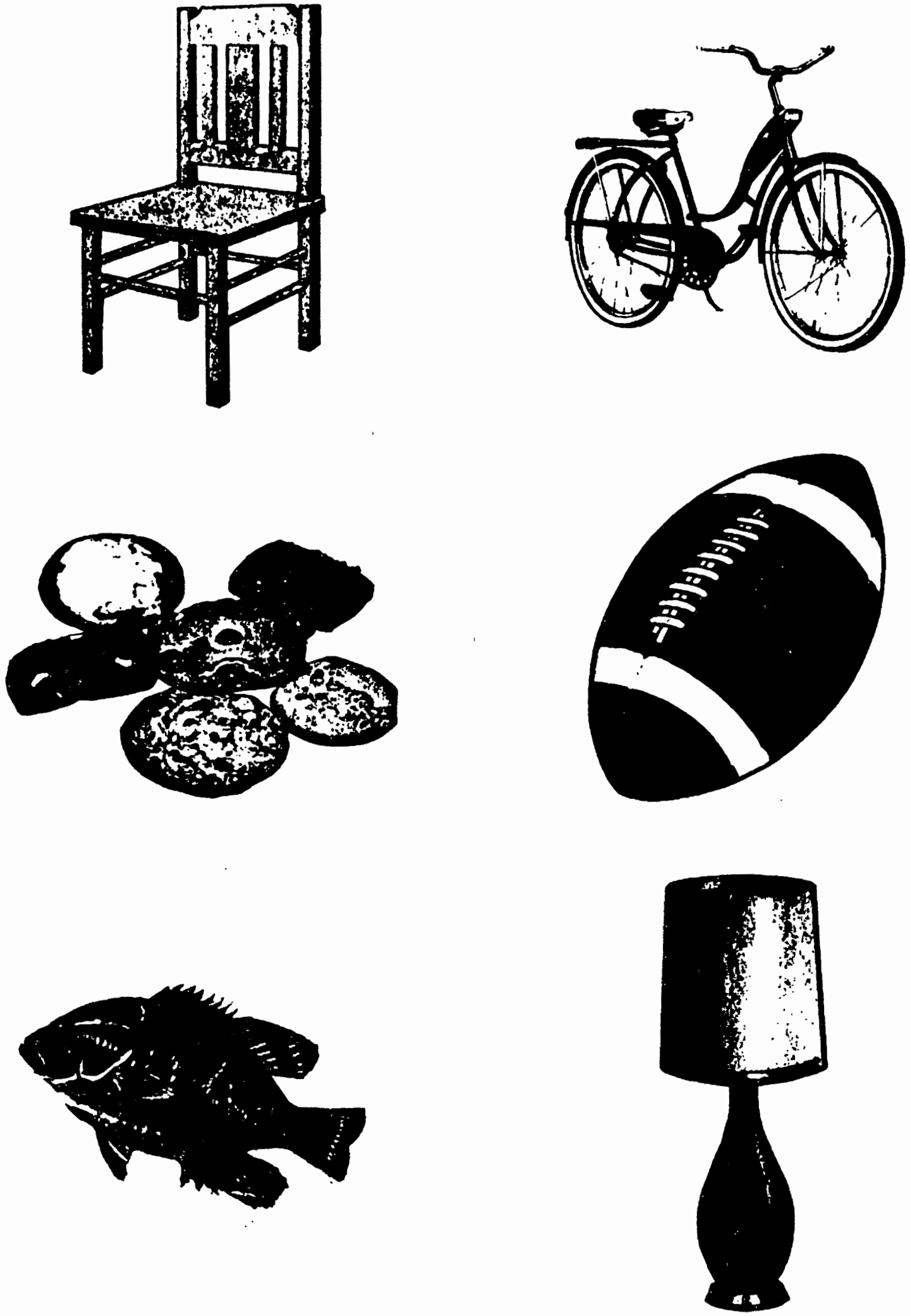

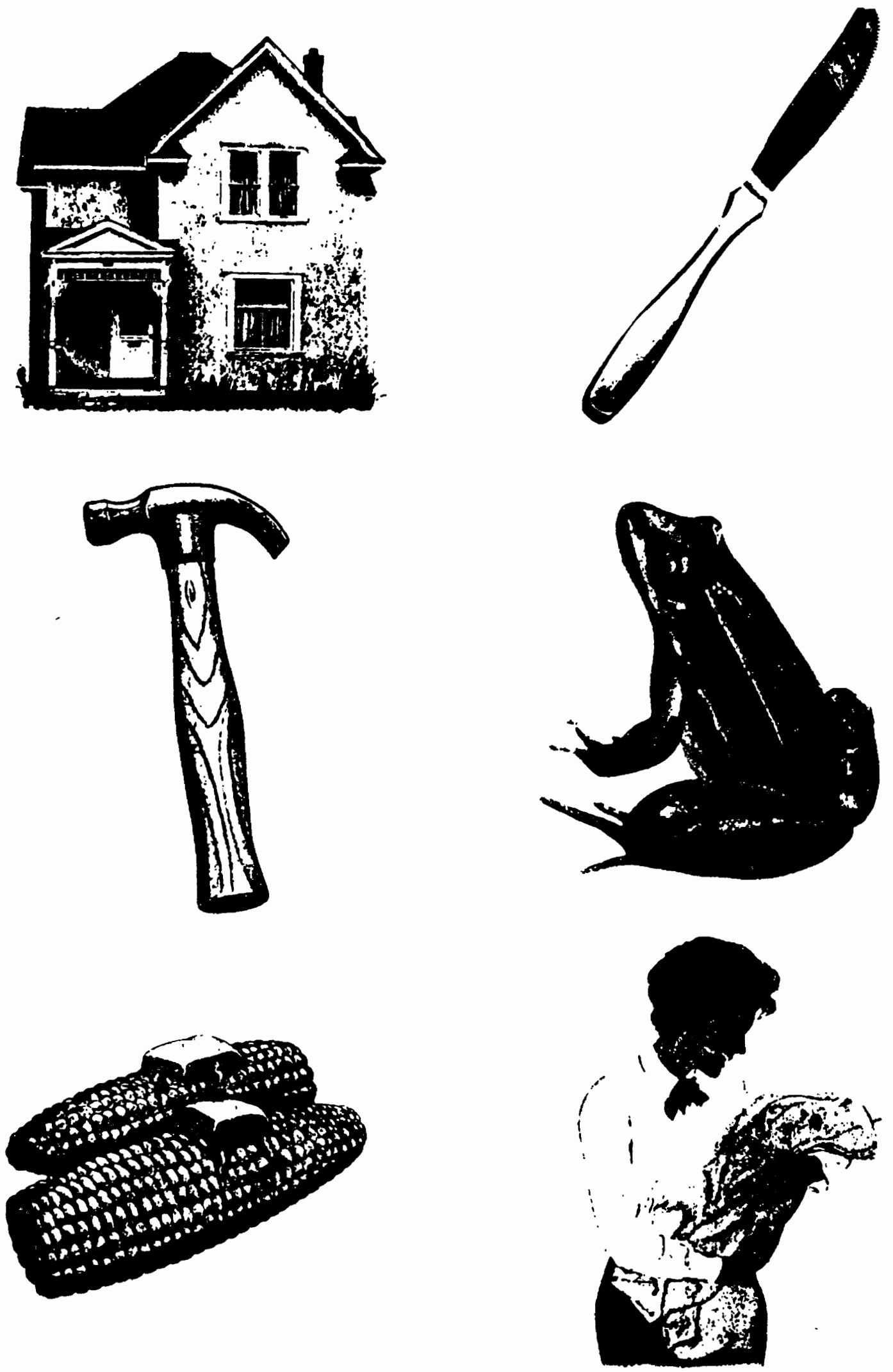


\section{APPENDIX G}

INSTRUMENTATION SPECIFICATIONS

Sony Tape Recorder Mode1 TC-105A

Frequency Response: $40-18,000 \mathrm{~Hz}$ at $7 \frac{1}{2}$ ips

Flutter and Wow: less than $0.12 \%$ at $7 \frac{1}{2}$ ips

Ampex Tape Recorder Mode1 AG-500

Frequency Response: at $7 \frac{1}{2} \mathrm{ips,}+2 \mathrm{~dB}, 60$ to $10,000 \mathrm{~Hz}$

Flutter and Wow: at $7 \frac{1}{2}$ ips, $0.13 \%$

$\mp 2-4 \mathrm{~dB}, 30$ to $15,000 \mathrm{~Hz}$

Signal-to-Noise Ratio: $52 \mathrm{~dB}$ or better

Electro-Voice Dynamic Microphone Mode1 635 A

Frequency Response: $80-13,000 \mathrm{~Hz}$

Polar Pattern: Omnidirectional

Impedance: Low (150 ohms)

Output Leve1: $-55 \mathrm{db}\left(0 \mathrm{db}=1 \mathrm{mw} / 10\right.$ dynes $\left./ \mathrm{cm}^{2}\right)$

EIA Sensitivity Rating: $-149 \mathrm{db}$

Ampex 1200 Grand Master Recording Tape

Frequency Response measured at $10 \mathrm{~dB}$ below $0 \mathrm{~dB}=185 \mathrm{nWb} / \mathrm{m}$

Bias adjusted for peak output at $500 \mathrm{~Hz}$

$1.5 \mathrm{mil}$

Backcoated

Beltone Audiometer Mode1 10-D

Accuracy of Frequency Calibration: Less than $2 \%$ variance of indicated frequency at all frequencies

Accuracy of SPL (Air Calibration): Within $3 \mathrm{~dB}$ of indicated level

Distortion: All harmonics of any frequency are no greater than $25 \mathrm{~dB}$ below the fundamental frequency

Tone Interruption: Approximately 0.1 second for complete rise and decay of tone

Signal to Noise Ratio: pure tone, $-60 \mathrm{~dB}$ or better 


\section{APPENDIX H}

\section{TEST INSTRUCTIONS}

"I am going to turn on a tape recorder. You will hear a lady telling you three things to do. I want you to listen very carefully to everything the lady says. When she stops talking, do exactly what she said to do. But don't do anything until she stops talking. Remember, do everything just like she tells you. Let's practice. If she says: 'Stand up,' show me what you will do. Good. If she says: 'Stand up, sit down,' show me what you will do. That's right, first you stand up, then you sit down. If she says: 'Stand up, clap your hands, sit down,' show me what you will do. Good. First you stand up, then you clap your hands, and you sit down last. Now listen to the lady on the tape."

If noise were to be presented in the background, the examiner added the following instructions before saying, "Now listen to the lady on the tape:"

"While the lady is talking you will hear a story at the same time. Don't listen to the story; only listen to the lady and do everything she says. Sometimes it might be hard to hear the lady, but just listen carefully and do just what she tells you. Just do your best."

On each subject's second day of 1istening skills testing, 
the examiner repeated the instructions as before, adding: "I want you to do the same thing you did last time. This time, though, there will/will not be a story at the same time. Do just what the lady says." : If noise were to be introduced during that session, the subject was given the same instructions to ignore the background as were those subjects presented noise during their first session. 